University of Montana

ScholarWorks at University of Montana

Graduate Student Theses, Dissertations, \&

Professional Papers

1971

\title{
The importance of mimic pattern and position in an artificial mimicry situation
}

Richard T. Shideler

The University of Montana

Follow this and additional works at: https://scholarworks.umt.edu/etd

Let us know how access to this document benefits you.

\section{Recommended Citation}

Shideler, Richard T., "The importance of mimic pattern and position in an artificial mimicry situation" (1971). Graduate Student Theses, Dissertations, \& Professional Papers. 6871.

https://scholarworks.umt.edu/etd/6871

This Thesis is brought to you for free and open access by the Graduate School at ScholarWorks at University of Montana. It has been accepted for inclusion in Graduate Student Theses, Dissertations, \& Professional Papers by an authorized administrator of ScholarWorks at University of Montana. For more information, please contact

scholarworks@mso.umt.edu. 


\title{
THE IMPORTANCE OF MIMIC PATTERN AND POSITION
}

\section{IN AN ARTIFICIAL MIMICRY SITUATION}

\author{
By
}

Richard T. Shideler

B. S. , University of Montana, 1968

Presented in partial fulfillment of the requirements for the degree of Master of Sciences

UNIVERSITY OF MONTANA

Approved by:

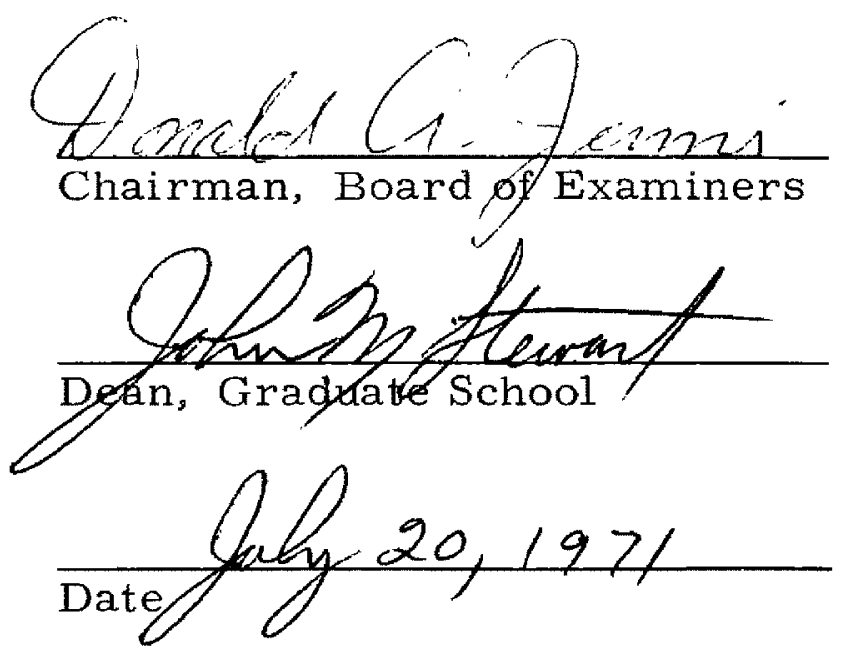


All rights reserved

INFORMATION TO ALL USERS

The quality of this reproduction is dependent upon the quality of the copy submitted.

In the unlikely event that the author did not send a complete manuscript and there are missing pages, these will be noted. Also, if material had to be removed, a note will indicate the deletion.

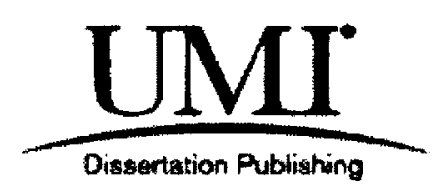

UMI EP37672

Published by ProQuest LLC (2013). Copyright in the Dissertation held by the Author.

Microform Edition () ProQuest LLC.

All rights reserved. This work is protected against unauthorized copying under Title 17, United States Code

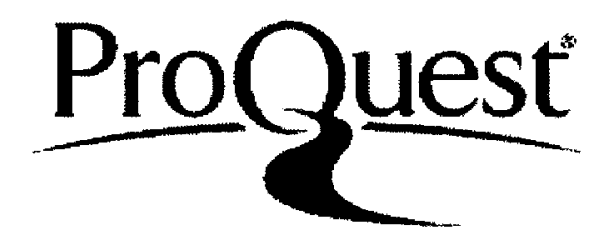

ProQuest LLC.

789 East Eisenhower Parkway

P.O. Box 1346

Ann Arbor, MI 48106 - 1346 


\section{ACKNOWLEDGEMENTS}

I wish to thank Dr. Donald Jenni for his encouragement and assistance throughout the course of this study. I would also like to thank Drs. Lee Metzgar and Andrew Sheldon for their helpful suggestions during the study.

Drs. Raymond Canham and Andrew Sheldon offered many helpful criticisms on the manuscript.

I would also like to thank my wife, Lee, for her encouragement and patience throughout this study.

During the study I was supported by a Teaching Assistantship from the Zoology Department. 
TABLE OF CONTENTS

Page

LIST OF TABLES . . . . . . . . . . . . . . . . iv

LIST OF FIGURES . . . . . . . . . . . . . . . . v v CHAPTER

I. INTRODUCTION . . . . . . . . . . . 1

II. METHODS . . . . . . . . . . . . . 4

The Predator . . . . . . . . . 4

The Prey. . . . . . . . . . 5

Experimental Procedure . . . . . 6

III. RESULTS . . . . . . . . . . . 9

The Advantage of Mimicry . . . . . 10

Predator Selection ......... 12

IV. DISCUSSION . . . . . . . . . 35

v. SUMMARY . . . . . . . . . . . . 39

REFERENCES . . . . . . . . . . . . . . 41

APPENDIX . . . . . . . . . . . . . . . 4 43

Appendix A . . . . . . . . . . . 43

Appendix B . . . . . . . . . . . . . . 44

Appendix C . . . . . . . . . . . . 45

Appendix D . . . . . . . . . . . . 46 


\section{LIST OF TABLES}

Table

I. Number of Mimics and Models Pecked (P),

Eaten (E), and Not Touched (NT) for All

Combinations

II. Wilcoxson Matched Pairs Signed Ranks Test. Difference between mean number edibles eaten per day and mean number of mimics eaten per day

III. Analysis of Variance Table for Position, Pattern, and Time. . . . . . . . . . . .

IV. Wilcoxson Matched Pairs Signed Ranks Test. Difference between mean number mimics eaten per day and mean number models eaten per day

V. Wilcoxson Matched Pairs Signed Ranks Test. Difference between mean number of models not touched and mean number of mimics not touched.

VI. Proportion of Mimics Eaten for Patterns and Positions . . . . . . . . . . . . . . . 


\section{LIST OF FIGURES}

Figure

Page

1. Mimic patterns and positions used . . . . . . .

2. Distribution of grand mean differences ( $\overline{\bar{d}})$ of mean number of mimics eaten minus mean number of models eaten for all patterns . . . . . . . . . . .

3. Distribution of grand mean differences ( $\overline{\bar{d}})$ of mean number of models not touched minus mean number of mimics not touched for all patterns . . . . . .

4. Distribution of grand mean differences $(\overline{\bar{d}})$ of mean number of edibles eaten (always 1.0) minus mean number of mimics eaten for all patterns . . . .

5. Effect of distance from model position on protection provided mimic patterns PABCF . • . . . . . . 26

6. Effect of distance from model position on protection provided mimic patterns DEG . . . . . . . . . 27

7. Effect of position on protection provided by mimic patterns PABCF . . . . . . . . . . . . 29

8. Effect of position on protection provided by mimic patterns DEG • • • • • • • • • • • . • . 30

9. Effect of position on whether the predator avoided the

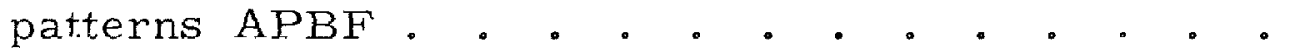

10. Effect of position on whether the predator avoided the mimic patterns ECDG . . . . . . . . . . 
CHAPTER I

\section{INTRODUCTION}

Natural selection is the principal guiding force in the modern ("synthetic") theory of evolution. The existence of adaptive systems maintained by natural selection has been documented (Ford 1956; Tinbergen 1965), but there are few instances in which the possible origins and development of a complex adaptive system have been critically studied. One of the more extensively studied adaptive systems is mimicry, the situation in which one organism bears a superficial resemblance to another. Mimicry also offers an excellent opportunity to study the effects of predator selection on a prey population. Batesian mimicry, in which a palatable prey individual (the mimic) resembles an unpalatable prey species (the model) has been identified in many taxa over the past century (reviewed in Wickler 1968). Excellent summaries of the observational and theoretical bases of Batesian mimicry theories, especially of the Papilio-Danaus butterfly complex, are given in Fisher (1958) and Ford (1964). Although the existence of Batesian mimicry has been hypothesized for some time, it is only recently that actual quantified field investigation proved that Batesian mimicry exists (Brower, Cook \& Croze 1967).

A series of laboratory experiments have demonstrated that various vertebrate predators learn to reject the models and their mimics in natural insect mimic-model complexes on the basis of $\epsilon x-$ ternal appearance alone (Brower 1958a, 1958b, 1958c; Brower \& Brower 1962, 1965; Brower, Brower \& Westcott 1960; others re- 
viewed by Brower 1963).

Some investigators have used laboratory studies to test various aspects of mimicry theory. Using caged starlings as predators and painted mealworms as artificial prey, Brower (1960) found that a mimic:model ratio of $6: 4$ afforded as much protection to the mimics as a mimic:model ratio of $3: 7$. Thus for the first time it was demonstrated that under conditions of perfect mimicry, the mimic could outnumber its model and be protected on the same order as a mimic which is outnumbered by its model. Even at a ratio of $9: 1$, about 17 per cent of the mimics escaped predation. Shideler (unpubl.), using the same technique as Brower (1960), independently verified her results.

Several investigators have dealt with the problem of the origin of mimetic resemblances--"incipient mimetic resemblances" as Schmidt (1960) calls them--in laboratory studies. Schmidt trained domestic chicks to avoid a drawing of a hypothetical model. He then offered the chicks choices of various "mimics," some of which had incorporated parts of the model's pattern. The chicks were rewarded or punished by being allowed to feed on chick mash (for the mimics) or chick mash mixed with potassium hydroxide (for the model). Schmidt found that a "summation effect" often occurred--i. e. the addition of individual components of the model's pattern to the mimic can result in avoidance greater than these components presented alone. Sexton (1960) found that predation on imperfect mimics was 
less than predation on the nonmimetic form. He also found that only those mimics which perfectly resembled the model escaped all predation. He used anoles (Anolis carolinensis) as the predator, adult mealworms (Tenebrio molitor) as the nonmimetic form, and fireflies (Photinus pyralis) as the models. His mimics were adult mealworms with the firefly's elytra, prothorax, or both, attached to the mealworm's dorsal surface.

Morrel \& Turner (1970) found that color was an important factor in mimetic resemblances, and that predators (urban birds) could discriminate between gross pattern differences on the mimics (pastry dummies with colored cards attached).

All of these studies involved mechanisms by which a potential mimic could evolve an appearance closely resembling the model. All involved changing the color or configuration of the mimics. The study reported here involves three of the mechanisms by which an organism could evolve a similarity to a model. One of these, the acquisition of the configuration of the model (hereafter termed "pattern") has been reported in the investigations previously mentioned. However, there is an additional component of the model's appearance, and that is the location of the particular configuration on the model (hereafter termed "position"). The third mechanism is the interaction of these two (pattern $x$ position). The aim of this study is to determine quantitatively the relative importance of pattern, position, and the effect of the interaction of these two variables. The experimental procedure also provides information on discrimination and generalization. 


\section{CHAPTER II}

METHODS

The experimental design basically follows that of Brower's (1960) original design, with some important exceptions which are mentioned in the following sections.

\section{The Predators}

The predators were caged starlings (Sturnus vulgaris) which were locally caught as wild adults. A total of fifty-five birds were captured, primarily by night-lighting and netting in abandoned barns. Five birds were caught on 24 March 1970 and 30 March 1970 in a poultry-wire magpie trap. Forty-two birds were caught on 4 April 1970 by night-lighting. In addition eight birds were also caught by wire trap from 1 June to 16 June 1970. Of the fifty-five birds, nine captured either died during captivity, or were too wild to be used in the experiments.

The birds were housed in a basement animal room of the Zoology Department, University of Montana, Missoula. The room was approximately $15^{\prime} \times 40^{\prime}$, with fluorescent lighting and a northfacing transluscent window which permitted some outside light to enter. 
The lights were on, except during experiments, from 0730 to 1700 . Animal caretakers and a few other persons visited the room several times during the day, except during the experiments.

Each bird was placed in a $30^{\prime \prime} \times 24^{\prime \prime} \times 24^{\prime \prime}$ hardware cloth cage. The cages were stacked along the west wall of the room, from ground to eye level. Individual cages were shifted to the tier approximately four feet high for the duration of the experiment.

Water and commercial bird food were available ad libitum at all times. They were not removed during the experiments.

\section{The Prey}

Mealworms (Tenebrio molitor) were used as prey. A large colony was maintained throughout the experiments. Only mealworms without obvious imperfections (discolored segments, etc.) were used. Although no exact measurements were taken, all mealworms used were approximately $1-1 / 8^{\prime \prime}(30 \mathrm{~mm})$ in length.

The mealworms were killed immediately before each experimental series by placing them in a small jar, and running hot water over the jar. This procedure killed the mealworms without disfiguring or discoloring them. Mealworms killed properly in this manner retained their color for over two hours. The prey were divided into three groups and treated as follows : 
Models: painted with a solid green band on the fourth and fifth abdominal segments, and dipped into a 66 per cent solution of quinine dihydrochloride to make them unpalatable.

Mimics: painted with green paint according to the patterns outlined in Fig. 1, and dipped into distilled water.

Edibles: painted with clear paint, and dipped into distilled water.

The mealworms were painted with Testor's PLA, a quick-drying cellulose paint.

There are seven abdominal segments on a mealworm. The abdominal segments were chosen because of their relatively uniform size. It was also possible to use a greater number of two-segment positions on the abdominal than on the thoracic segments. Seven mimic patterns were used (Fig. 1), including three complementary pairs. If the two members of the pair were superimposed over one another, the model's pattern resulted. The seventh pattern was a hypothetical "supernormal stimulus" consisting of a three-segment solid band. All seven mimic patterns and the perfect (model's) pattern were used at all positions.

\section{Experimental Procedure}

Once the starlings readily ate untreated mealworms, even with the prepared food available, the experiment was initiated.

In order to exclude the possibility of birds receiving unconscious cues from the observer, observations were made behind a 
Fig. 1. Mimic patterns and positions used. " $P$ " is the perfect (model) pattern. Position 4 is the model position. Scale: approximately $1 \frac{1}{2} \mathrm{x}$. 


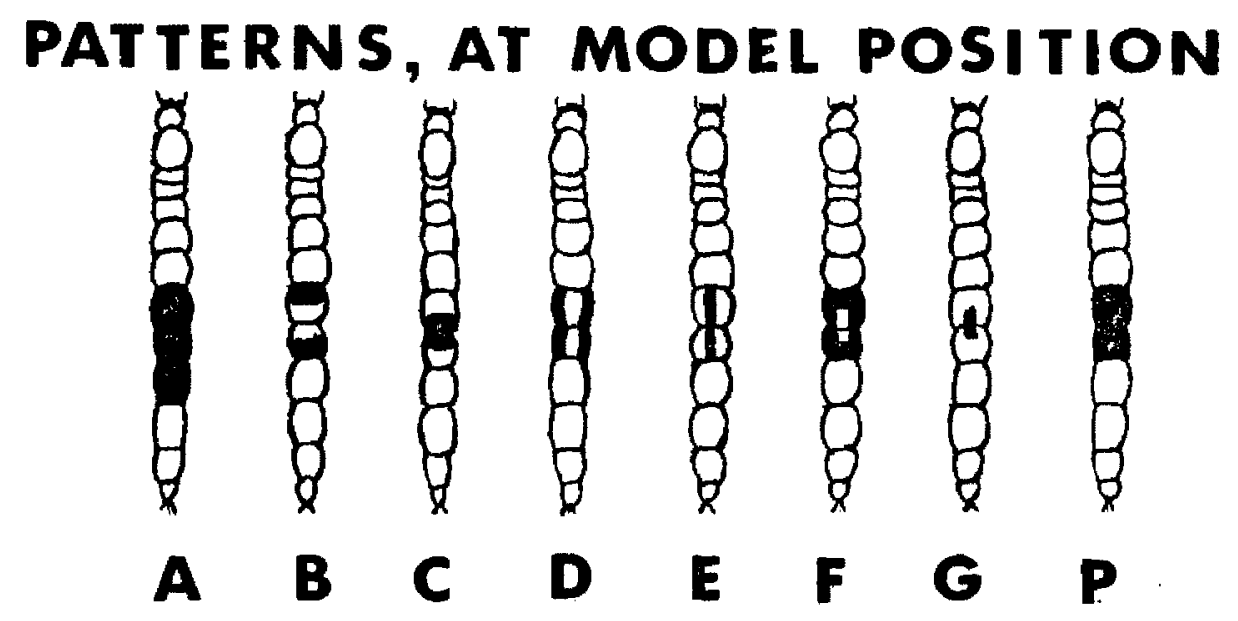

POSITIONS, WITH MODEL PATTERN

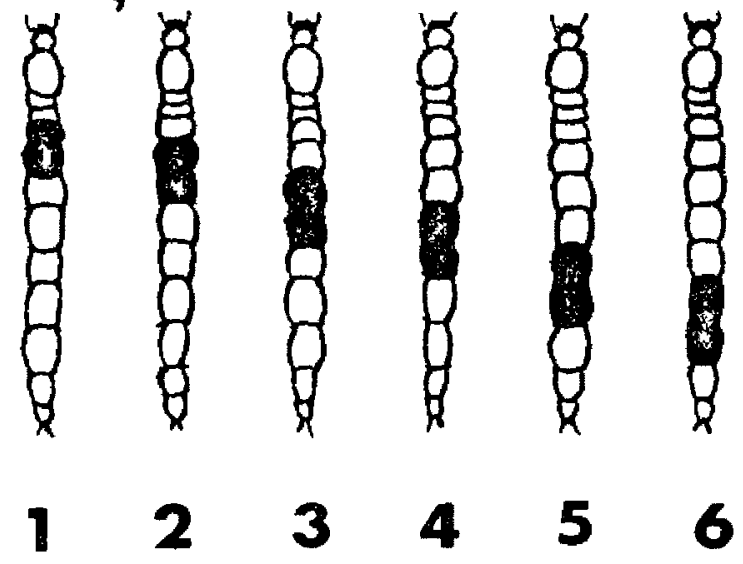




\section{COMBINATIONS}
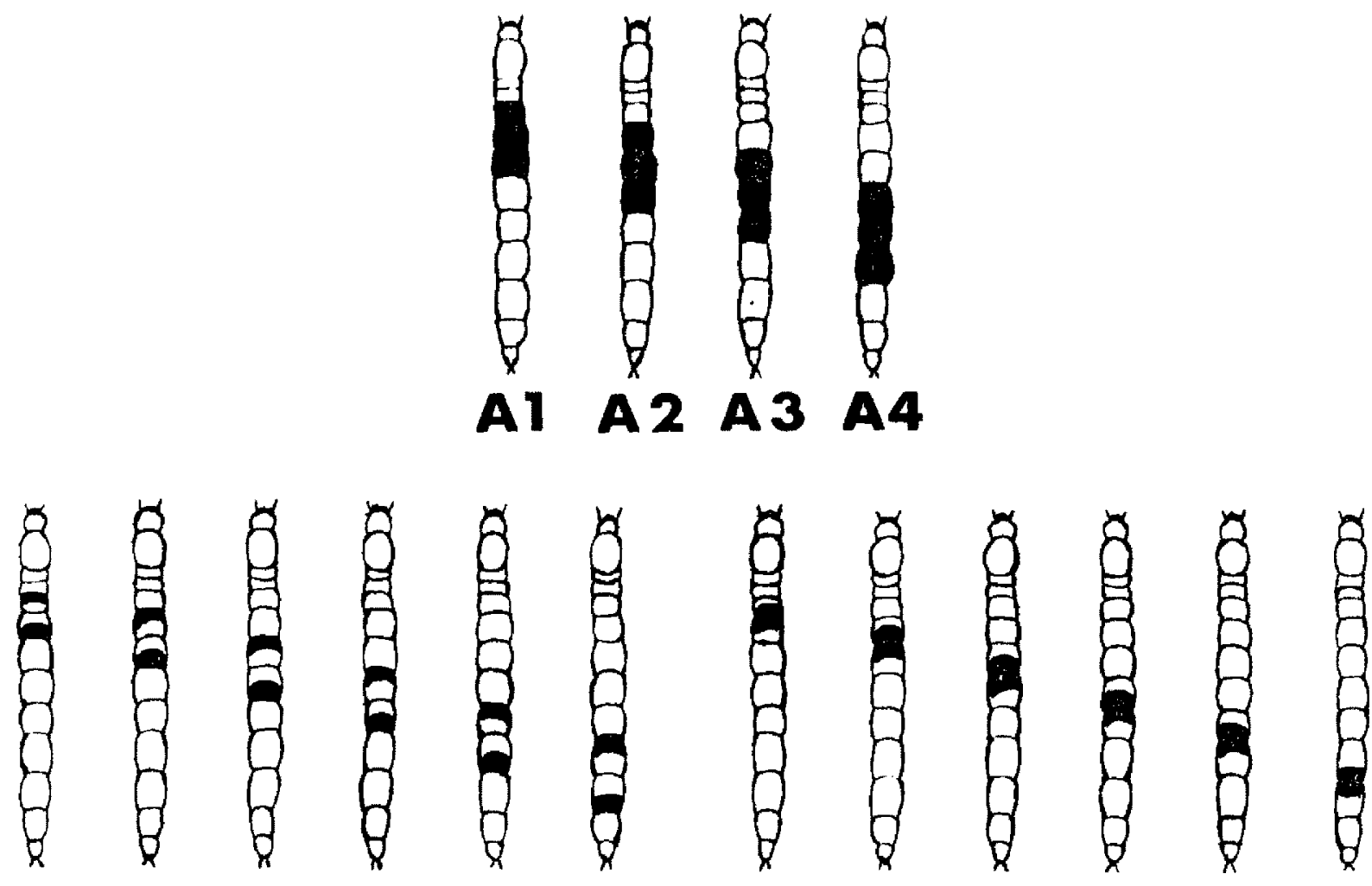

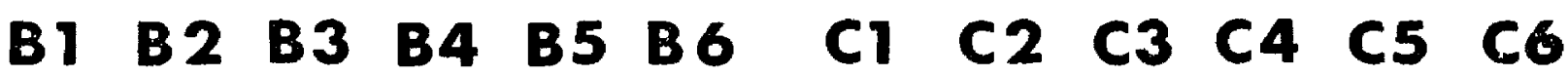

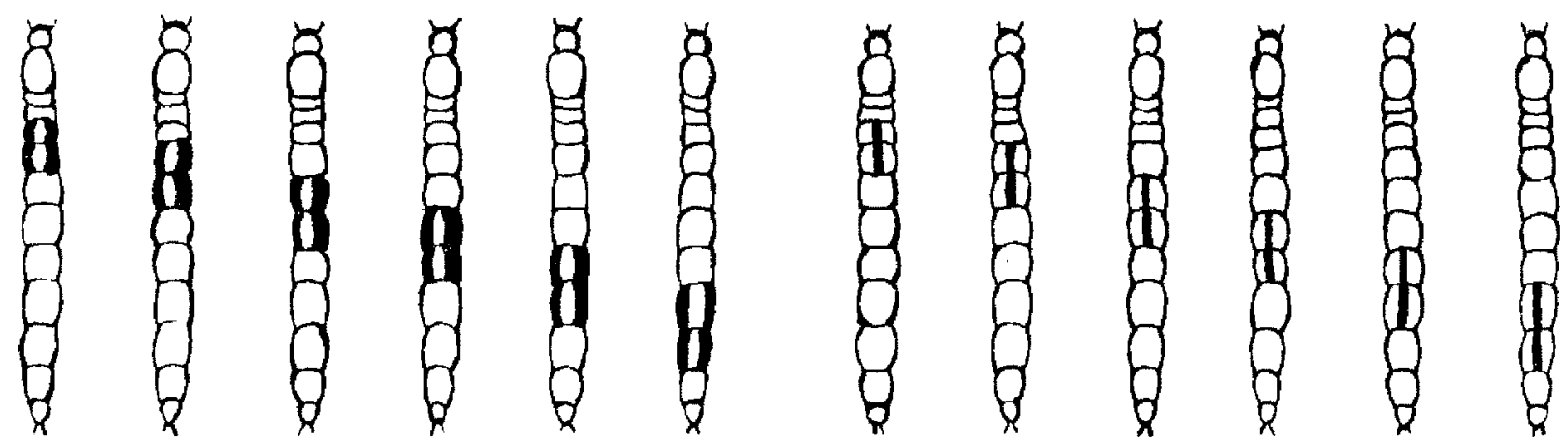

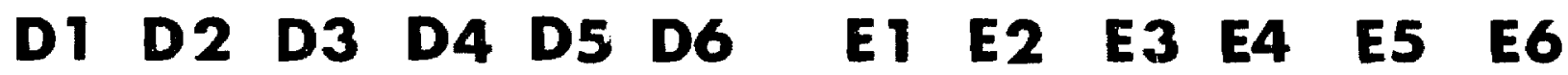

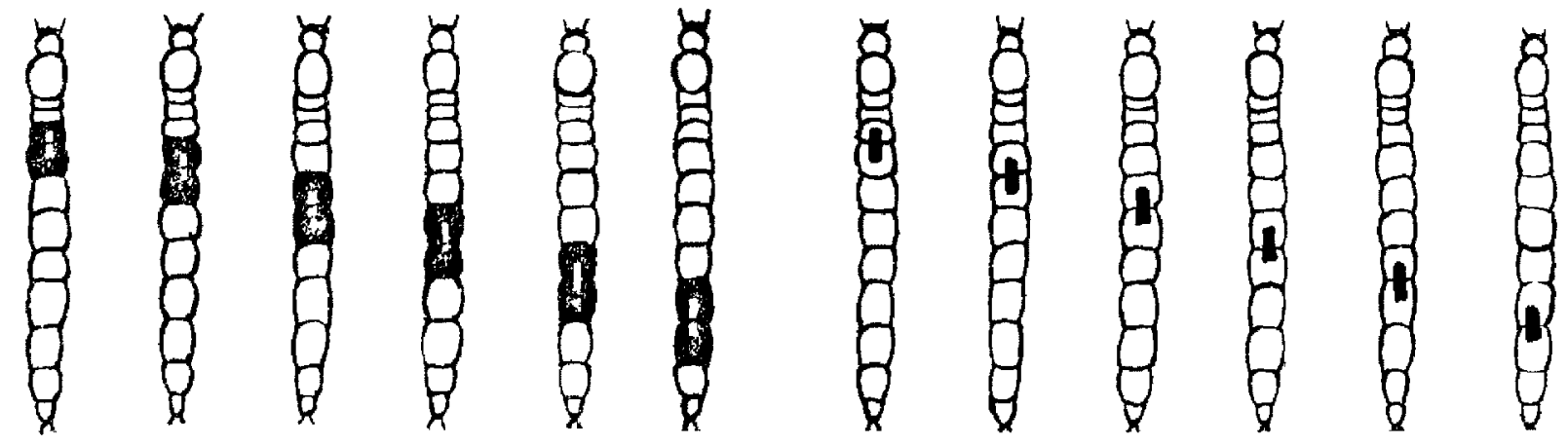

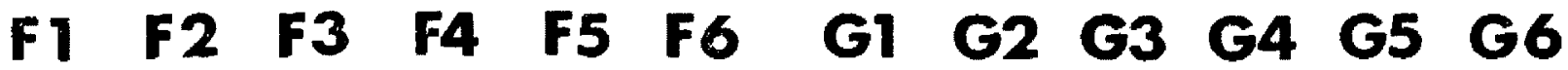


"light blind." Two 100-watt bulbs mounted in 12 " reflectors on two $5^{\prime}$ high stands were placed $3^{\prime}$ apart, and $3^{\prime}$ to $4^{\prime}$ in front of the cage. The lights were shown on the cage being used, and the room lights extinguished. A human observer sitting approximately $5^{\prime}$ behind this "light blind," could not be distinguished by another human in front of the lights. The birds showed no apparent aversion to this lighting arrangement, and at no time did they seem to be receiving cues from the observer.

Immobilized prey were presented singly on a piece of white filter paper in a $4^{\prime \prime}$ petri dish. The prey was left in the cage for 60 seconds, and the starling could eat $(E)$ the worm, peck $(P)$ but not eat it, or not touch (NT) it. During the 60 seconds, latency in seconds for the activity was scored by stopwatch, and other observations on the bird's behaviour noted. After 60 seconds, the mealworm was removed and the bird's responses recorded on the prepared sheets.

Each of the patterns and positions shown in Fig. 1 was tested by a "series" of experiments. A series consisted of ten trials per day for ten consecutive days. A "trial" consisted of sequential presentation of one edible mealworm and either a model or mimic. The order of presentation within each trial was determined randomly using a random numbers table, and the order of presentation of the five mimics and five models on one day was also determined randomly. This precluded the bird's learning the order of presentation and 
responding to that rather than to clues from the prey.

Each series was run on one experimentally naive starling. Thus each bird received over a ten day period a total of 100 edibles, 50 mimics, and 50 models. A mimic:model ratio of $1: 1$ was used in all series.

If a bird failed to eat an edible during any trial on one day, the results for that trial were not used, and the series was discontinued for that day. The results for trials previous to the trial in which the bird rejected the edible were used.

In order to at least partially standardize the bird's exposure to noxious stimuli, all birds were "pre-conditioned." Pre-conditioning consisted of offering the birds only models and edibles, using the same procedure as the actual experiment, until the bird rejected five successive models on each of two successive days. In almost all cases, the birds met the criterion within the first two days. Birds which could not be pre-conditioned within three or four days were not used. Most of the birds not meeting the criterion would eat neither models nor edibles. 
CHAPTER III

RESULTS

The first part of the results deals with the protection of mimics as shown by comparison of numbers of mimics and of edibles eaten and time required for the predator to eat those which were eaten. The second part deals with predator discrimination and generalization of the patterns and positions used.

\section{Advantage of Mimicry}

For all combinations, at least a few of the mimics were not eaten, they were either pecked and dropped, or not touched at all. Table I lists the numbers of mimics and models pecked, eaten, and not touched. For a particular mimic pattern and position to be effective, the mimics must be eaten significantly fewer times than the edibles. The number of mimics eaten compared to the number of edibles eaten was tested using a Wilcoxson Matched Pairs Signed Rank Test (Siegel 1956). The mean number of mimics eaten per day was subtracted from the mean number of edibles eaten per day for each combination. Since, according to the criteria for a successful experiment, all edibles must be eaten, the mean number of edibles eaten per day is always 1.0. The results for this test (Appendix A) indicate that there was a significant difference at the 0.1 level between the edibles and mimics eaten for all pattern-position combinations except B3 and G5. The most reasonable explanation for the lack of significance is that the predators tested on these two combinations represent one ex- 
Table I. Number of Mimics and Models Pecked (P), Eaten (E), and Not Touched (NT) for All Combinations. Position 4 is the Model Position, Pattern $P$ is the Model Pattern.

\section{Position}

1 Mimic Model
2

\section{Mimic Model}

3

Mimic Mode1

$\begin{array}{llllllllllllllll}P & E N T & P & E\end{array}$
A 12320
141619
$\begin{array}{lll}3 & 7 & 40\end{array}$
131225
$\begin{array}{lll}6 & 43 & 1\end{array}$
$\begin{array}{lll}34 & 12 & 4\end{array}$
B $\quad \begin{array}{llllll}7 & 33 & 10 & 19 & 27 & 4\end{array}$
$3 \quad 16 \quad 31$
$\begin{array}{llll}7 & 7 & 36\end{array}$
$149 \quad 0$
$\begin{array}{lll}18 & 31 & 1\end{array}$
$\begin{array}{lllllll}\text { C } & 1 & 45 & 3 & 14 & 25 & 11\end{array}$
$\begin{array}{lll}1 & 35 & 14\end{array}$
$\begin{array}{lll}1 & 30 & 19\end{array}$
$\begin{array}{lll}0 & 37 & 10\end{array}$
$\begin{array}{lll}4 & 34 & 11\end{array}$
$\begin{array}{lllllll}\mathrm{D} & 3 & 39 & 7 & 24 & 5 & 21\end{array}$
$\begin{array}{lll}9 & 35 & 3\end{array}$
$\begin{array}{lll}27 & 17 & 3\end{array}$
$\begin{array}{lll}4 & 46 & 0\end{array}$
$\begin{array}{lll}29 & 19 & 2\end{array}$
$\begin{array}{lllllll}\mathrm{E} & 2 & 43 & 5 & 28 & 7 & 15\end{array}$
$\begin{array}{llllll}1 & 42 & 7 & 25 & 19 & 6\end{array}$
$\begin{array}{lll}0 & 19 & 31\end{array}$
$\begin{array}{lll}8 & 3 & 38\end{array}$
$\begin{array}{lllllll}\text { F } & 4 & 45 & 1 & 6 & 43 & 1\end{array}$
$\begin{array}{llllll}2 & 40 & 8 & 14 & 24 & 12\end{array}$
$13 \quad 1816$
$\begin{array}{lll}18 & 5 & 24\end{array}$
$\begin{array}{lllllll}\text { G } & 1 & 48 & 1 & 37 & 7 & 6\end{array}$
$\begin{array}{lll}0 & 39 & 9\end{array}$
$\begin{array}{lll}5 & 13 & 24\end{array}$
$\begin{array}{lll}0 & 43 & 7\end{array}$
$\begin{array}{lll}7 & 14 & 29\end{array}$
$\begin{array}{llll}\mathrm{P} & 3 & 47 & 0\end{array}$
$\begin{array}{lll}9 & 41 & 0\end{array}$
$\begin{array}{lll}17 & 26 & 7\end{array}$
$\begin{array}{lll}21 & 15 & 14\end{array}$
52916
$\begin{array}{lll}21 & 10 & 19\end{array}$

\section{Position}

\begin{tabular}{cccccccc}
\multicolumn{1}{c}{4} & \multicolumn{2}{c}{5} & \multicolumn{2}{c}{6} \\
Mimic & Model & Mimic & Model & Mimic & Model \\
P E NT & P E NT & P E NT & P E NT & P E NT & P E NT
\end{tabular}

$\begin{array}{lllllll}\text { A } & 1 & 46 & 3 & 11 & 34 & 5\end{array}$

$\begin{array}{lllllll}\mathrm{B} & 10 & 5 & 35 & 22 & 0 & 28\end{array}$

$\begin{array}{lll}4 & 34 & 11\end{array}$

$12 \quad 1920$

$\begin{array}{lll}3 & 39 & 8\end{array}$

131720

$\begin{array}{lllllll}\text { C } & 12 & 2711 & 21 & 623\end{array}$

12029

$\begin{array}{lll}6 & 13 & 31\end{array}$

13910

$\begin{array}{lll}14 & 19 & 17\end{array}$

$\begin{array}{lllllll}\mathrm{D} & 6 & 35 & 4 & 21 & 14 & 10\end{array}$

$6 \quad 34 \quad 10$

$\begin{array}{lll}16 & 10 \quad 24\end{array}$

42521

$\begin{array}{lll}20 & 722\end{array}$

$\mathrm{E} \quad 2 \quad 43 \quad 3 \quad 21 \quad 21 \quad 6$

$\begin{array}{llll}2 & 45 & 3\end{array}$

$\begin{array}{lll}12 & 29 & 9\end{array}$

13811

$\begin{array}{lll}13 & 20 & 17\end{array}$

$\begin{array}{lllllll}\text { F } & 5 & 31 & 14 & 19 & 17 & 12\end{array}$

$\begin{array}{lll}6 & 42 & 2\end{array}$

$\begin{array}{lll}11 & 34 & 5\end{array}$

$10 \quad 35 \quad 5$

$\begin{array}{lll}14 & 23 & 13\end{array}$

$\begin{array}{lllllll}\mathrm{G} & 0 & 46 & 4 & 29 & 13 & 8\end{array}$

$\begin{array}{lll}1 & 49 & 0\end{array}$

$\begin{array}{lll}7 & 39 & 4\end{array}$

$\begin{array}{lll}3 & 47 & 0\end{array}$

$19 \quad 19 \quad 12$

$\mathrm{P}$

$\begin{array}{lll}4 \quad 9 & 37\end{array}$

$\begin{array}{lll}6 & 4 & 40\end{array}$

$\begin{array}{lll}322 & 22\end{array}$

6 1428 
treme of individual variation in predator behaviour.

The data were then arranged so that all the position combinations of a particular pattern were lumped under each of the patterns, and then all pattern combinations of a particular position were lumped under each position. The Wilcoxson test was then run to see if each position, regardless of pattern, and each pattern, regardless of position, was provided significant protection when compared to the edibles (Table II). The results indicated a significant difference $(P<0.005)$ for all patterns and positions.

The longer a predator delays before taking a prey, the more time the prey has to escape, and, under natural conditions, the more likely the predator is to be distracted by other stimuli. When latency to eat was compared for edibles and mimics eaten of all combinations, the time required to eat the mimics was significantly greater than the time required to eat the edibles. This indicates that, under natural conditions, there would be a greater chance for the mimic to survive.

\section{Predator Selection}

A Three-Way Analysis of Variance (Simpson, Roe \& Lewontin 1960) was used to test the differences among the combinations, using mean number of mimics eaten per day during a period of ten days. All three sources of variation, pattern, position, and time, are significant, as is the pattern $x$ position interaction. Position $x$ time and pattern $x$ time are not significant (Table III). If one assumes that the time factor is due to learning, and hence not a random factor, the Fixed Model 
Table II. Wilcoxs on Matched Pairs Signed Ranks Test, Differences Between Mean Number Edibles Eaten Per Day and Mean Number Mimics Eaten Per Day. $N=$ number of matched pairs, $T=$ smaller sum of like-signed ranks (Siegel 1956).

\begin{tabular}{|c|c|c|c|c|c|c|c|}
\hline \multicolumn{8}{|c|}{ Pattern } \\
\hline$P$ & A & B & C & $\mathrm{D}$ & $\mathrm{E}$ & $F$ & G \\
\hline$N=45$ & $N=24$ & $N=38$ & $N=38$ & $\mathrm{~N}=40$ & $N=34$ & $N=43$ & $N=17$ \\
\hline $\mathrm{T}=0$ & $\mathrm{~T}=0$ & $\mathrm{~T}=0$ & $\mathrm{~T}=0$ & $\mathrm{~T}=0$ & $T=0$ & $\mathrm{~T}=0$ & $T=0$ \\
\hline$p<.005$ & $p<.005$ & $p<.005$ & $p<.005$ & $p<.005$ & $p<.005$ & $\mathrm{p}<.005$ & $p<.00$ \\
\hline
\end{tabular}

Position

1

$\mathrm{N}=37$

$\mathrm{T}=0$

$\mathrm{p}<.005$
2

$\mathrm{N}=59$

$\mathrm{T}=0$

$p<.005$
3

$\mathrm{N}=47$

$\mathrm{T}=0$

$p<.005$
4

$\mathrm{N}=43$

$\mathrm{T}=0$

p<. 005
5 6

$\mathrm{N}=49$

$\mathrm{T}=0$

$p<.005$
$\mathrm{N}=48$

$\mathrm{T}=0$

$p<.005$ 
Table III. Analysis of Variance Table for Position, Pattern, and Time. " $F$ " Values for Fixed Model Not in Parentheses; " $F$ " Values for Mixed Model in Parentheses.

\begin{tabular}{|c|c|c|c|c|c|c|c|}
\hline SOURCE & $\mathrm{S}$ & is & $\mathrm{df}$ & & MS & $\mathbf{F}$ & $\mathrm{P}$ \\
\hline Position & 20 & 021 & 5 & 4 & 004 & $7.76(8.09)$ & $<0.025$ \\
\hline Pattern & 45 & 831 & 6 & 7 & 639 & $14.79(17.52)$ & $<0.005$ \\
\hline Time & 26 & 119 & 9 & 2 & 902 & $5.62 \quad(5.62)$ & $<0.005$ \\
\hline Pattern x Position & 139 & 049 & 30 & 4 & 635 & 8.98 & $<0.005$ \\
\hline Position $\mathrm{x}$ Time & 22 & 297 & 45 & & 495 & 1.0 & NS \\
\hline Pattern $x$ Time & 23 & 549 & 54 & & 436 & 1.0 & NS \\
\hline $\begin{array}{c}\text { Pattern x Time } \\
\text { x Position }\end{array}$ & 139 & 137 & 270 & & 516 & & \\
\hline Total & 416 & 063 & 419 & & & & \\
\hline
\end{tabular}


ANOVA is appropriate, and the denominator of the main effects ratios is the second order interaction (pattern $x$ position $x$ time). If one assumes that time is a random factor, the Mixed Model is appropriate. The denominators of the main effects ratios are then the first order interactions. The data have been treated both ways. The "F" values presented for the Fixed Model are not in parentheses. The "F" values for the Mixed Models are in parentheses. Probability values are the same for both models. The results are significant for both models.

The Analysis of Variance indicates that pattern is more likely to contribute to the differences than position (" $P$ " values for pattern are lower than for position). It does not distinguish between individual patterns and between individual positions. It has been shown earlier that the predators discriminate edibles and mimics (Table II). It is possible that predators are generalizing from the model to any mealworm with green paint on it, rather than discriminating. If the predators are generalizing, the number of mimics eaten should not differ significantly from the number of models eaten. However, the amount of predation on all combinations was significantly different from the amount of predation on the models except for F1 and C2 (Wilcoxson test, $P=0.08$ for $B 1, P<0.05$ for all other combinations, Appendix $C$ ). If all positions for each pattern and all patterns for each position are lumped as was done previously, there are significant differences between the numbers of models and mimics eaten for all patterns and positions (Table IV). 
Table IV. Wilcoxson Matched Pairs Signed Ranks Test. Difference Between Mean Number Mimics Eaten per Day and Mean Number Models Eaten per Day. N, T as in Table II.

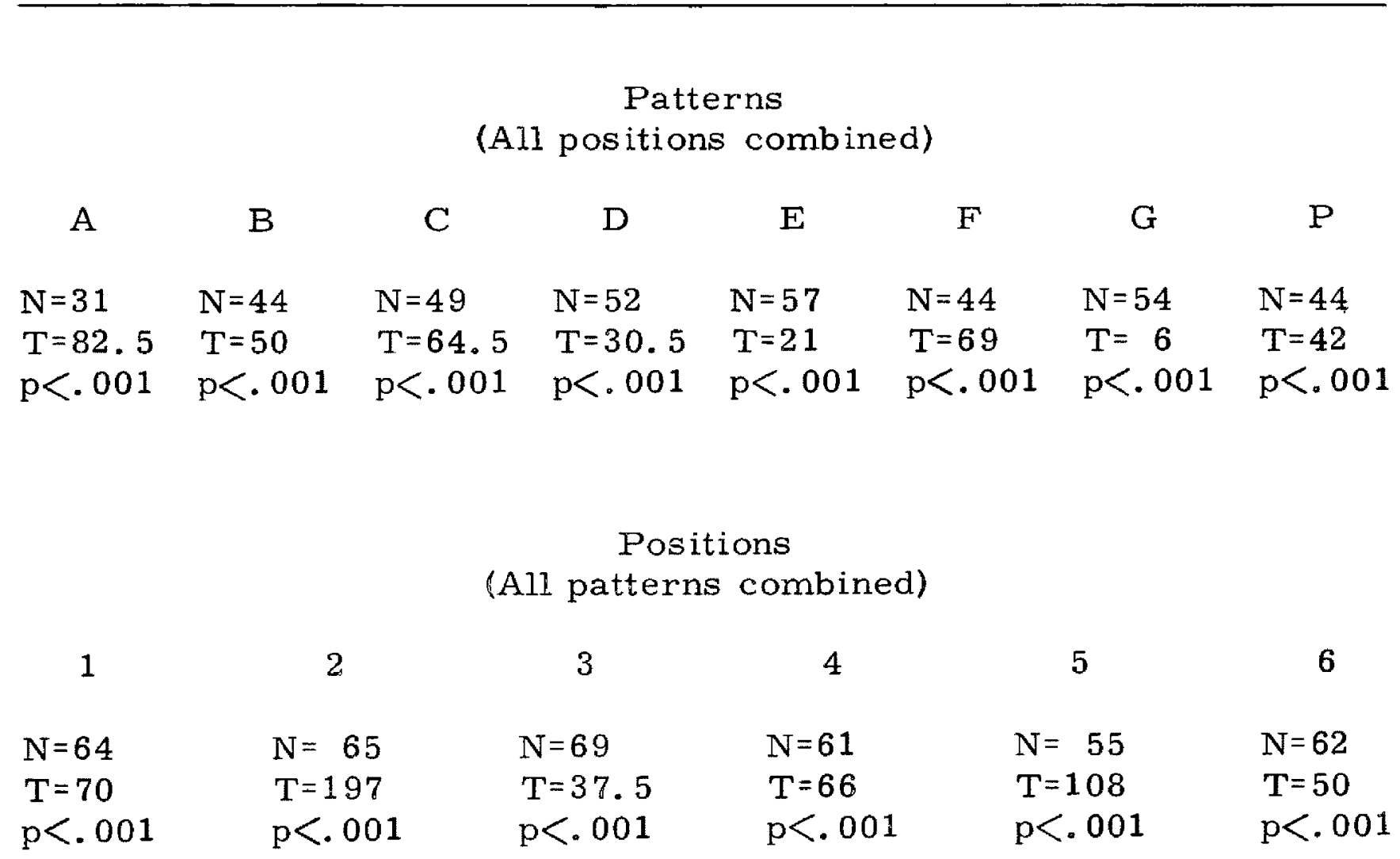


Visual discrimination by the birds is best measured by comparing the proportions of mimics and models not touched. There was no significant difference between the mean number of models and mimics not touched per day for several of the combinations (Wilcoxson test, Appendix D). However, all mimics, lumped by patterns and positions, as was done previously, were touched significantly more times than the models (Table V). Thus the birds did discriminate not only between the mimics and edibles, but also between the mimics and models. Though they may be generalizing, they are also discriminating.

The mean number of mimics eaten for each of the patterns are shown in Table VI. These values must be interpreted with care because they do not include the birds' reaction to the model. If a bird were generalizing and eating many models as well as mimics, the mean would be high for that particular pattern, but there would be little indication that the bird was discriminating the mimics from the model. Therefore it was desirable to analyze the degree of difference between the numbers of models and mimics eaten by the birds. For each combination, the mean number of models eaten per day was subtracted from the mean number of mimics eaten per day, summed for the ten days, and divided by ten to give a $\bar{d}$ value. These $\bar{d}$ values were then lumped by pattern as was done previously. The sum of the $\bar{d}$ 's for each pattern was then divided by the number of combinations 
Table V. Wilcoxs on Matched Pairs Signed Rank Test. Difference Between Mean Number of Models Not Touched per Day and Mean Number of Mimics Not Touched per Day. N, T as in Table II.

\section{Patterns \\ (All positions combined)}
A
B
$\mathrm{C}$
$\mathrm{D}$
$\mathrm{E}$
F
G
$\mathrm{P}$

$\begin{array}{llllllll}\mathrm{N}=27 & \mathrm{~N}=35 & \mathrm{~N}=42 & \mathrm{~N}=41 & \mathrm{~N}=37 & \mathrm{~N}=31 & \mathrm{~N}=40 & \mathrm{~N}=36 \\ \mathrm{~T}-96 & \mathrm{~T}=233 & \mathrm{~T}=219.5 & \mathrm{~T}=229 & \mathrm{~T}=151 & \mathrm{~T}=128 & \mathrm{~T}=58.5 & \mathrm{~T}=209 \\ \mathrm{p}=.01 & \mathrm{p}=.09 & \mathrm{p}<.01 & \mathrm{p}=.005 & \mathrm{p}<.001 & \mathrm{p}=.01 & \mathrm{p}<.001 & \mathrm{p}=.03\end{array}$

\section{Positions \\ (All patterns combined)}

1

$\mathrm{N}=44$

$\mathrm{T}=278$

$\mathrm{p}=.01$
2

$\mathrm{N}=60$

$\mathrm{T}=444.5$

$\mathrm{p}<.001$
$\mathrm{N}=45$

3

$\mathrm{T}=206$

$\mathrm{p}<.001$
4

$\mathrm{N}=46$

$\mathrm{T}=373$

$\mathrm{p}=.03$
5

$\mathrm{N}=41$

$\mathrm{T}=158.5$

$\mathrm{p}<.001$
6

$\mathrm{N}=52$

$\mathrm{T}=294$

$\mathrm{p}<.001$ 
Table VI. Proportions of Mimics Eaten for Patterns and Positions. Based on Mean Numbers of Mimics Eaten per Day.

\begin{tabular}{|c|c|c|c|c|c|c|c|}
\hline \multicolumn{8}{|c|}{$\begin{array}{l}\text { Patterns } \\
\end{array}$} \\
\hline A & $\mathrm{B}$ & $\mathrm{C}$ & D & $\mathbf{E}$ & $\mathrm{F}$ & G & $\mathbf{P}$ \\
\hline 00.63 & 0.59 & 0.69 & 0.73 & 0.74 & 0.71 & 0.91 & 0.59 \\
\hline \multicolumn{8}{|c|}{$\begin{array}{l}\text { Positions } \\
\text { (All patterns combined) }\end{array}$} \\
\hline & 1 & 2 & 3 & 4 & 5 & 6 & \\
\hline & 0.83 & 0.61 & 0.72 & 0.71 & 0.67 & 0.79 & \\
\hline
\end{tabular}


contributing to that pattern to give a grand mean value $(\overline{\bar{d}})$ for that pattern. The $\overline{\overline{\mathrm{d}}}$ 's fall into three distinct groups, FPBAC, ED, and G (Fig. 2). The same type of analysis comparing mimics and models not touched yields four groups--A, PBF, ECD, and G (Fig. 3). Because these $\overline{\bar{d}}$ 's are based upon the proportion of mimics eaten or not touched, and on the proportion of models eaten or not touched, either a low proportion of models or a high proportion of mimics could inflate the values. In order to determine if the distribution of $\overline{\bar{d}}$ 's obtained in Figs. 2 and 3 were due to variations in the proportions of mimics rather than models, which the predator sampled, a comparison of differences between the number of mimics eaten and edibles eaten was made. If the distribution of $\overline{\mathrm{d}}$ 's for mimics and edibles eaten was similar to those obtained in Figs. 2 and 3 , one would expect that these earlier distributions were due to variation in the predator's ability to discriminate the mimic, because the proportion of edibies eaten is constant (1.0) for all combinations. In Fig. 4, the results for distribution of $\overline{\bar{d}}$ 's for mimics and edibles eaten are given. There are three main groups--P, ABCFDE, and $G$. Comparing all three distributions from Figs. 2, 3 and 4, there appear to be three main groups--APBFC, $D E$, and G--although the order of occurrence within a group differs among the three figures.

Position is significant (Table III), but how the position effects the starling's choice has not been analyzed. There are several 
Fig. 2. Distribution of grand mean differences $(\overline{\bar{d}})$ of mean number of mimics eaten minus mean number of models eaten for all patterns. 


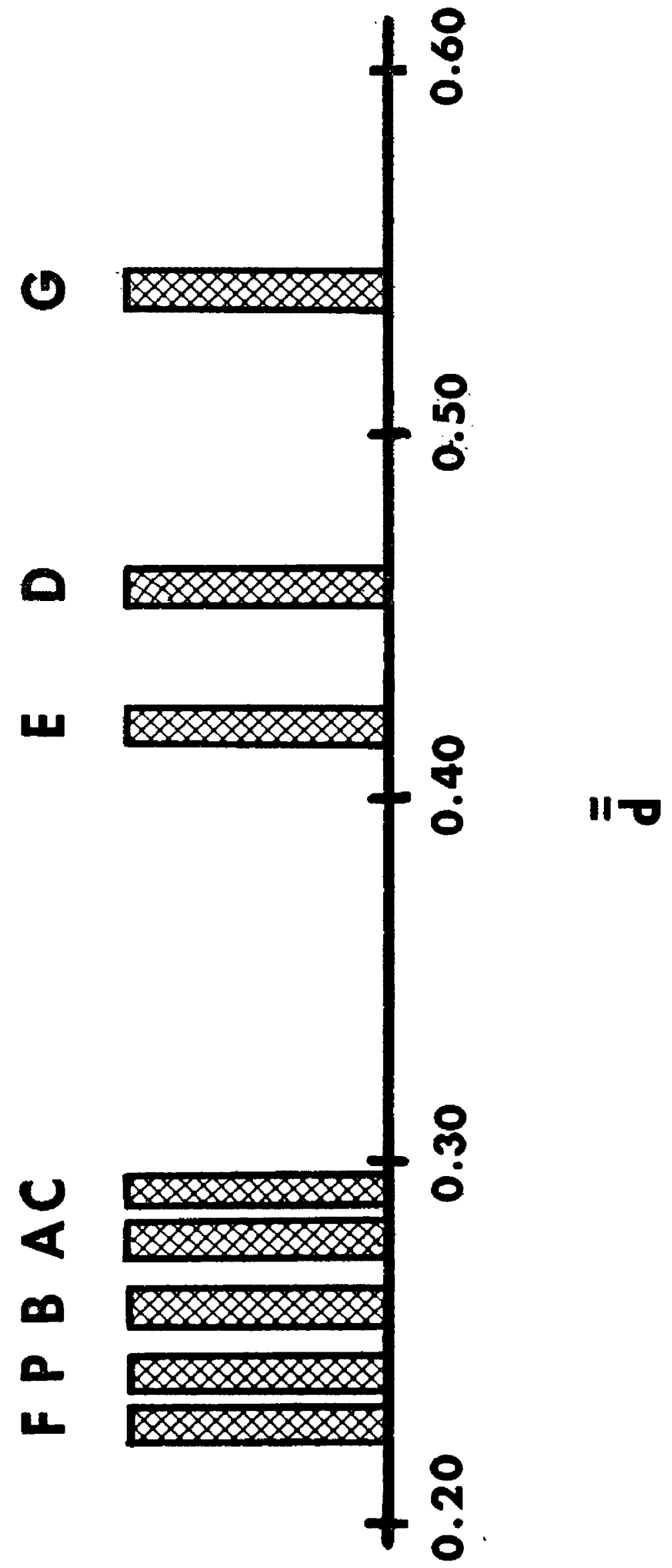


Fig. 3. Distribution of grand mean differences $(\overline{\bar{d}})$ of mean number of models not touched minus mean number of mimics not touched for all patterns. 


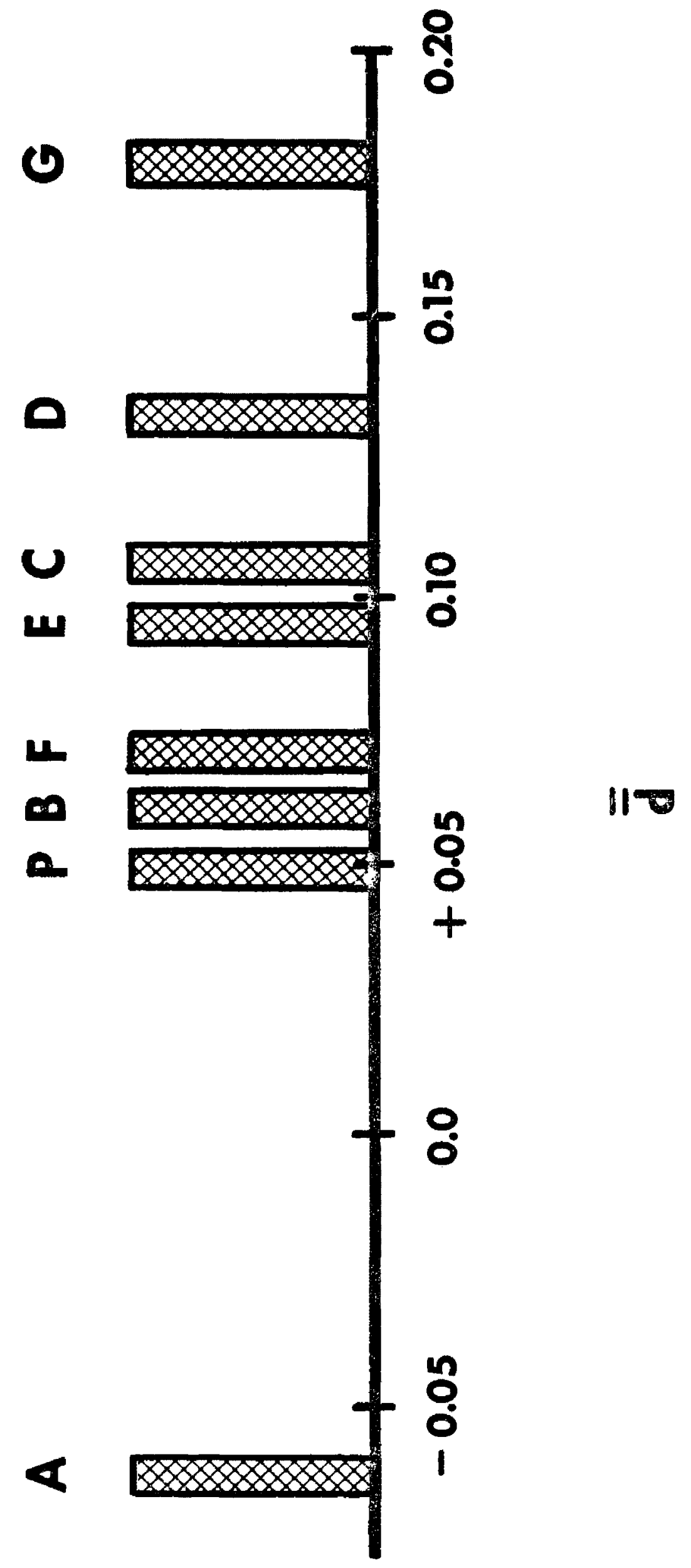


23

Fig. 4. Distribution of grand mean differences $(\overline{\bar{d}})$ of mean number of edibles eaten (always 1.0) minus mean number of mimics eaten for all patterns. 


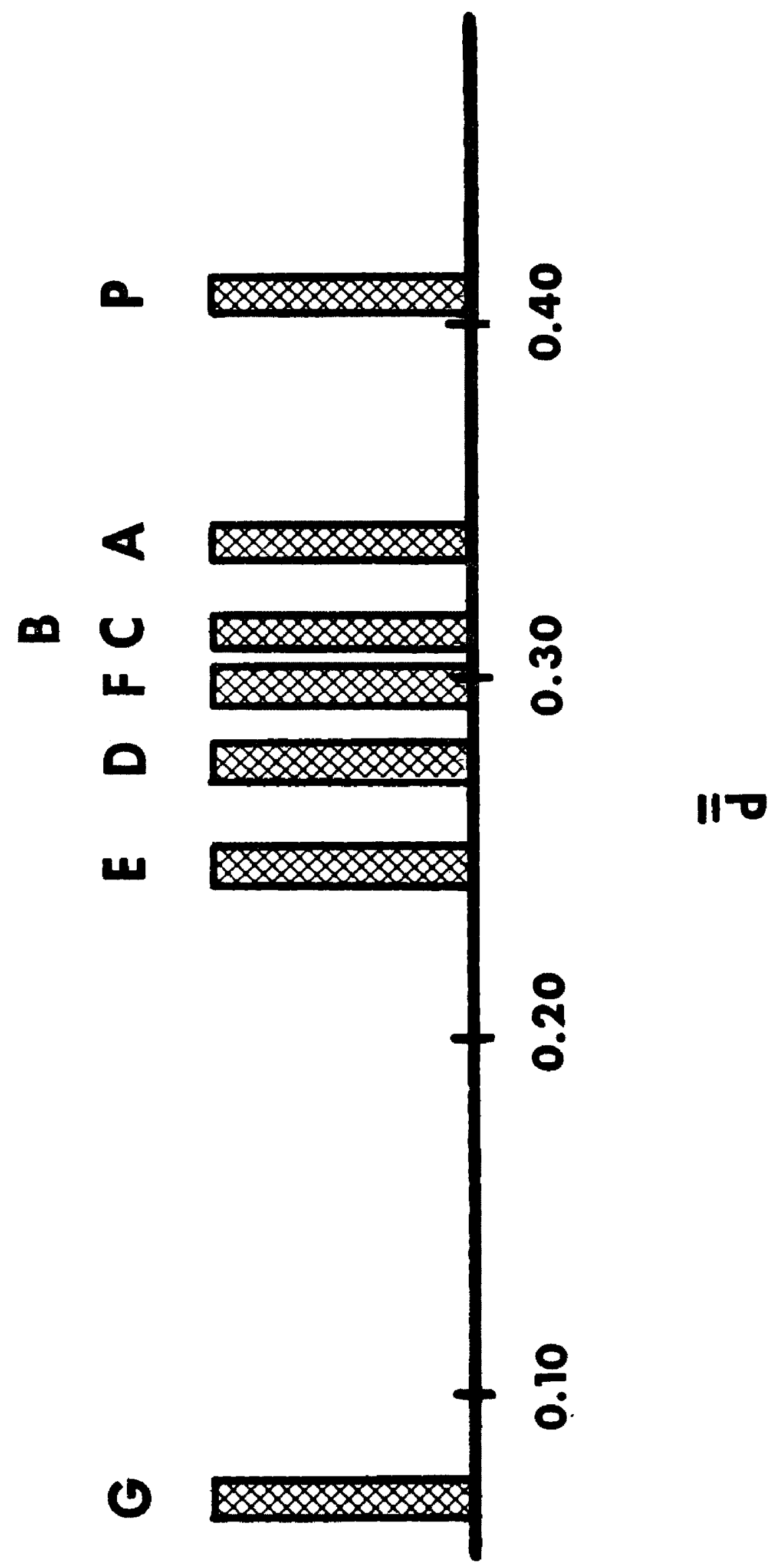


possibilities regarding predator discrimination and position effects. The first possibility is that the predator may be relating the distance between the mimic position and model position, regardless of the direction of change or relation to the rest of the mealworm. A second possibility is that the birds relate the position to the entire worm, but without distinguishing whether the direction of change is anterior or posterior. A third possibility is that the birds are discriminating head and tail of the mealworm, and that responses to changes in an anterior direction are not necessarily the same as those to changes in the posterior direction. In this case, position 1, being the most anterior position, should be discriminated more easily than position 4, although both are equidistant from the ends of the mealworm. There are other alternatives including a combination of these three possibilities, but these are the main position effects which this experiment could test. Because APFBC and DEG were clumped separately in Figs. 2,3 and 4, they were analyzed separately for position effects also. The proportion of mimics eaten minus the proportion of models eaten was compared, because number eaten is the most important factor in determining predator selection on the mimic patterns. The $\overrightarrow{\mathrm{d}}$ values used in calculating $\overline{\bar{d}}$ for patterns were recombined to analyze the various possibilities for position effects, using the lumping technique used for patterns.

The $\overline{\bar{d}}$ 's, standard errors of the mean, and ninety-five per cent 
confidence intervals for the mean are compared on modified Dice diagrams (Simpson et al. 1960) in Figs. 5 and 6. These two diagrams compare distance from the model position, regardless of direction, so that positions 3 and 5 are one segment from the model position, positions 2 and 6 two segments, etc. All confidence intervals overlap for both pattern groups APFBC and DEG. However, the standard error of the mean accounts for sixty-eight per cent of the variation about the sample mean. The standard error of the mean for position 1, pattern group DEG, does not overlap the standard error of the mean of other positions (Fig. 6) indicating a slight tendency for the birds to respond to position 1 of this pattern group differently than the other positions.

Correlation coefficients for these two groups show that for APFBC, there was no significant difference $(r=.045, P>0.1, d f=26)$ between the distance from position 4 and the difference between models and mimics eaten. For the DEG group, there is a significant correlation $(r=519, P<0.05, d f=16)$, indicating that as the positions diverged from the model position, the starlings were able to distinguish more of the mimics.

However, a high correlation coefficient could be the result of a very high correlation in one direction from the model position masking a low negative correlation, or none at all, in the opposite direction. To test this possibility, the six positions must be analyzed separately for the same pattern groups, rather than lumping them as was done in 
Fig. 5. Effect of distance from model position on protection provided mimic patterns PABCF. Mean number of mimics eaten minus mean number of models eaten (a mean score of zero means protection equal to the model; a positive score means protection less than the model; a negative score means protection greater than the model). Comparison of $\bar{a}$ (horizontal line), standard error of the mean (box), and ninety-five per cent confidence interval (vertical line). Position 4 is the model position. 
PABCF

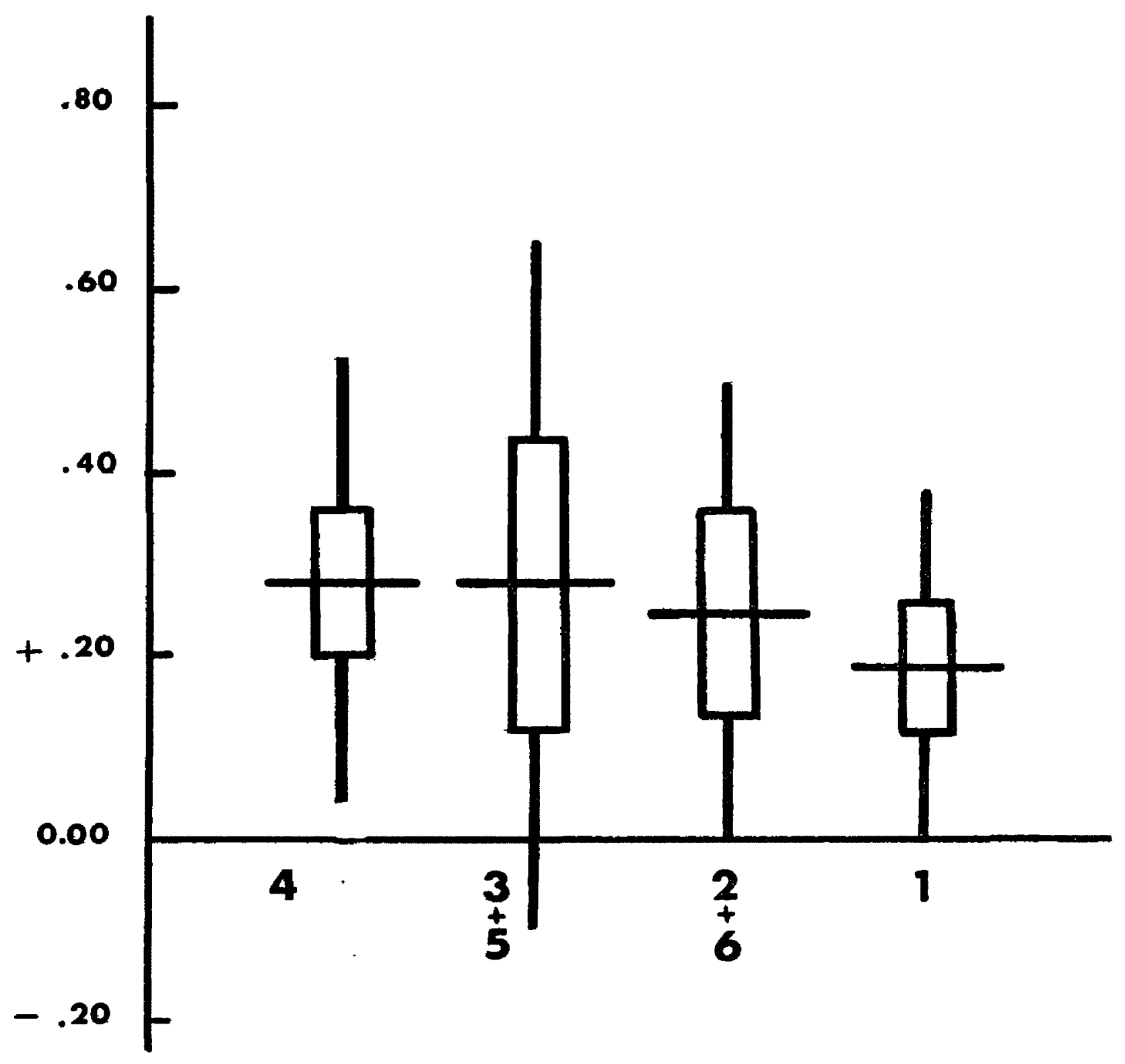

POSITION

Reproduced with permission of the copyright owner. Further reproduction prohibited without permission. 
Fig. 6. Effect of distance from model position on protection provided mimic patterns DEG. Mean number of mimics eaten minus mean number of models eaten. Comparison of $\overline{\bar{d}}$, standard error of the mean, and ninety-five per cent confidence interval. Position 4 is the model position. Symbols as in Fig. 5. 


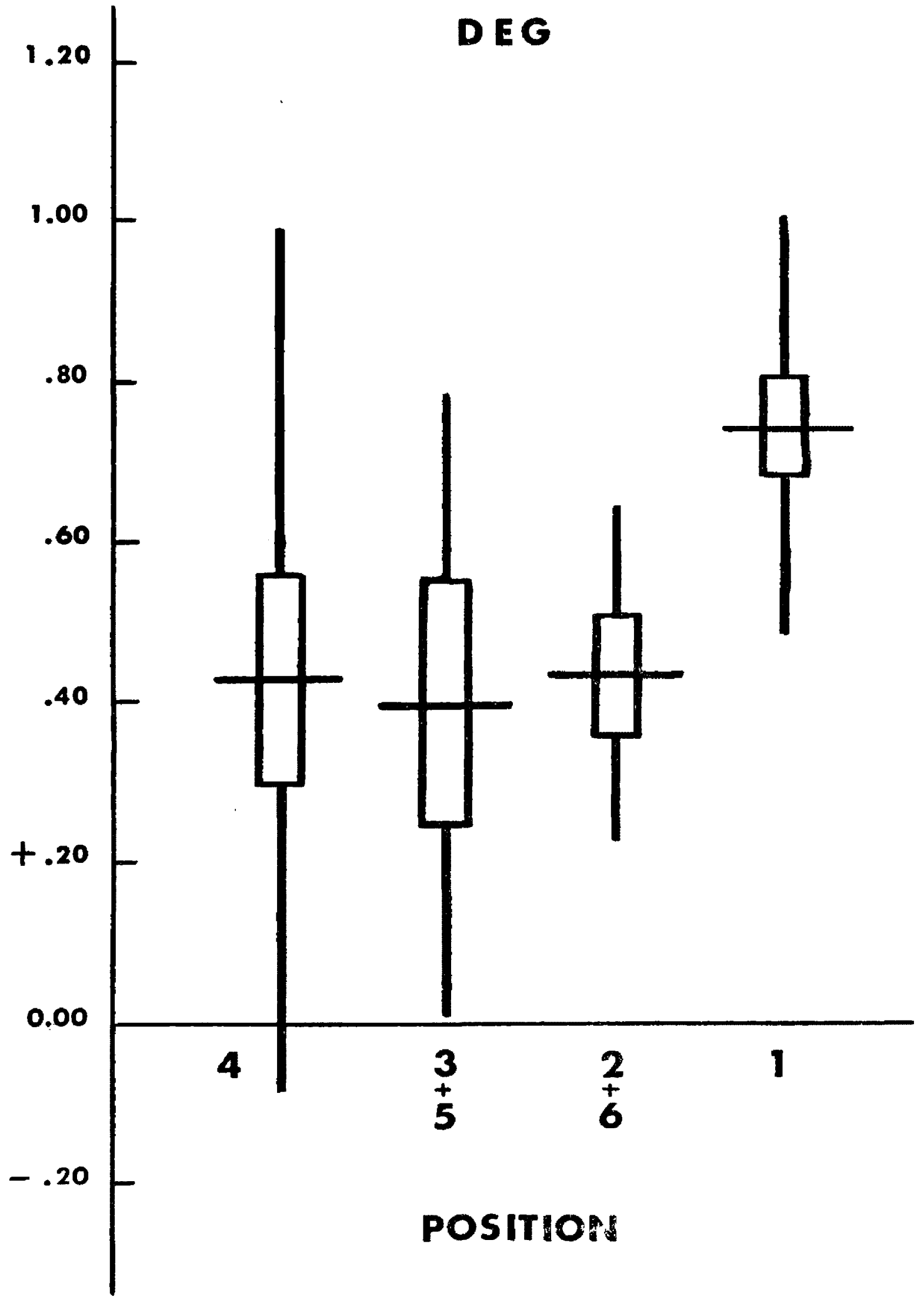


the preceding analysis (Figs. 7 and 8). All confidence intervals overlap, so that there is no indication the birds were responding differently to individual positions. Correlation coefficients were calculated for positions 4 through 6 , and 1 through 4 for each pattern group. For APFBC, no significant correlations were found for either positions 1 through $4(r=.309, P>0.1, d f=18)$ or 4 through $6(r=.130, P>0.1$, df $=11$ ). For pattern group DEG, there was a significant negative correlation from position 1 through $4(\mathrm{r}=-.610, \mathrm{P}<0.05, \mathrm{df}=10)$, but no significant correlation from positions 4 through $6(r=-.018, P>0.1$, $d f=7$ ). In addition, for the DEG group, a significant negative correlation was found from position 1 through $6(r=-.633, \quad P<0.01, \mathrm{df}=16)$. Thus the predators discriminated the mimic patterns DEG on the most anterior positions more often than on the most posterior segments. These three patterns are the ones which least resemble the model.

The mean numbers of mimics and models not touched at each of the positions were also compared. Because the patterns aligned differently for the response "not touched, " than they did for "eaten," (compare Figs. 2 and 3) the patterns were analyzed in four groups-PBF with and without A (Fig. 9), and ECD with and without G (Fig. 10). As explained in the Methods section, there were no combinations for A5 and A6. The confidence intervals overlapped for all positions in the four pattern groups.

These data were also analyzed with correlation coefficients. 
Fig. 7. Effects of position on protection provided by mimic patterns PABCF. Mean number of mimics eaten minus mean number of models eaten. Comparison of $\overline{\bar{d}}$, standard error of the mean, ninety-five per cent confidence interval. Position 4 is the model position. Symbols as in Fig. 5. 


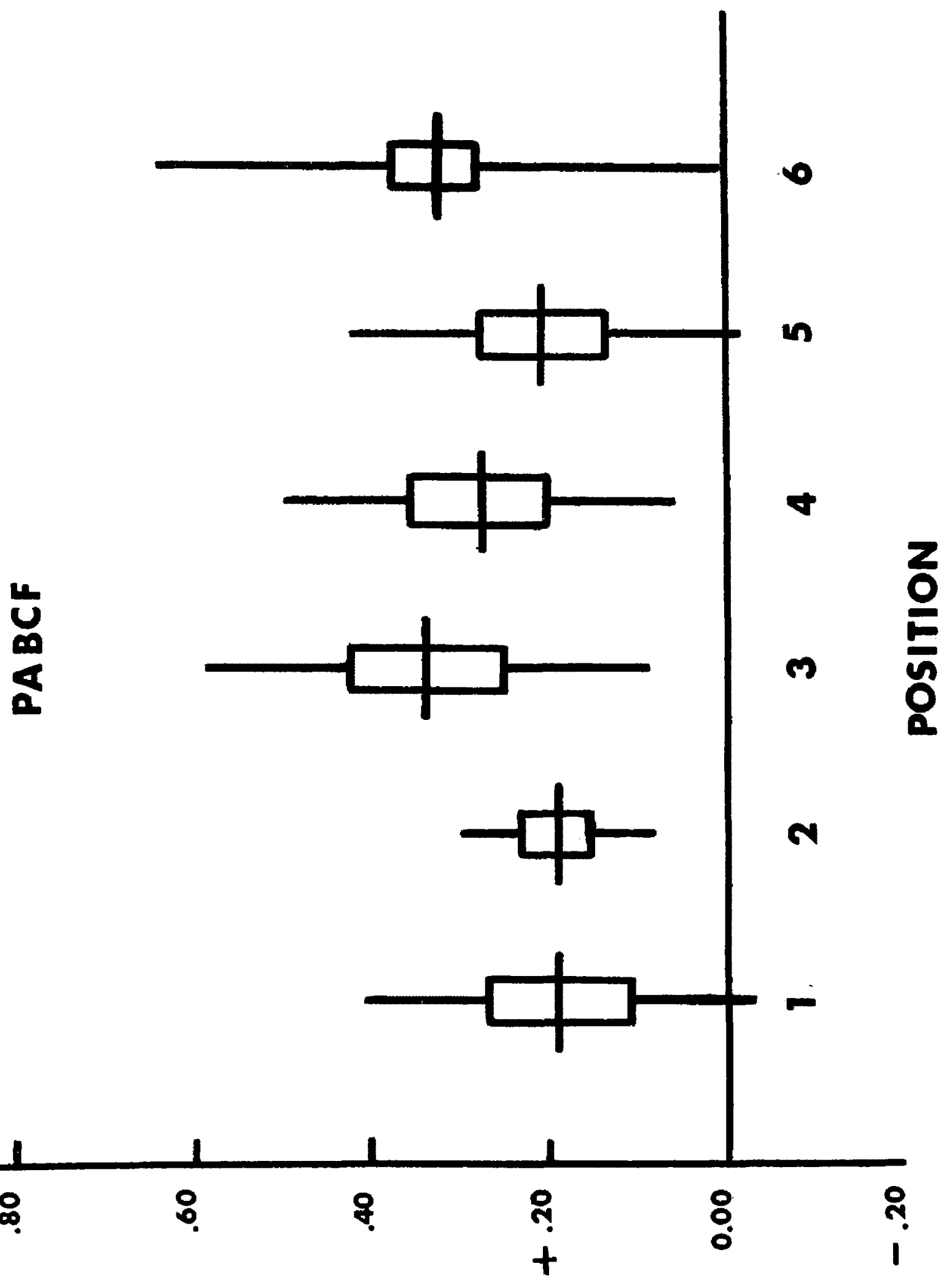


Fig. 8. Effect of position on protection provided mimic patterns DEG. Mean number of mimics eaten minus mean number of models eaten. Comparison of $\overline{\bar{d}}$, standard error of the mean, and ninety-five per cent confidence interval. Position 4 is the model position. Symbols as in Fig. 5 . 


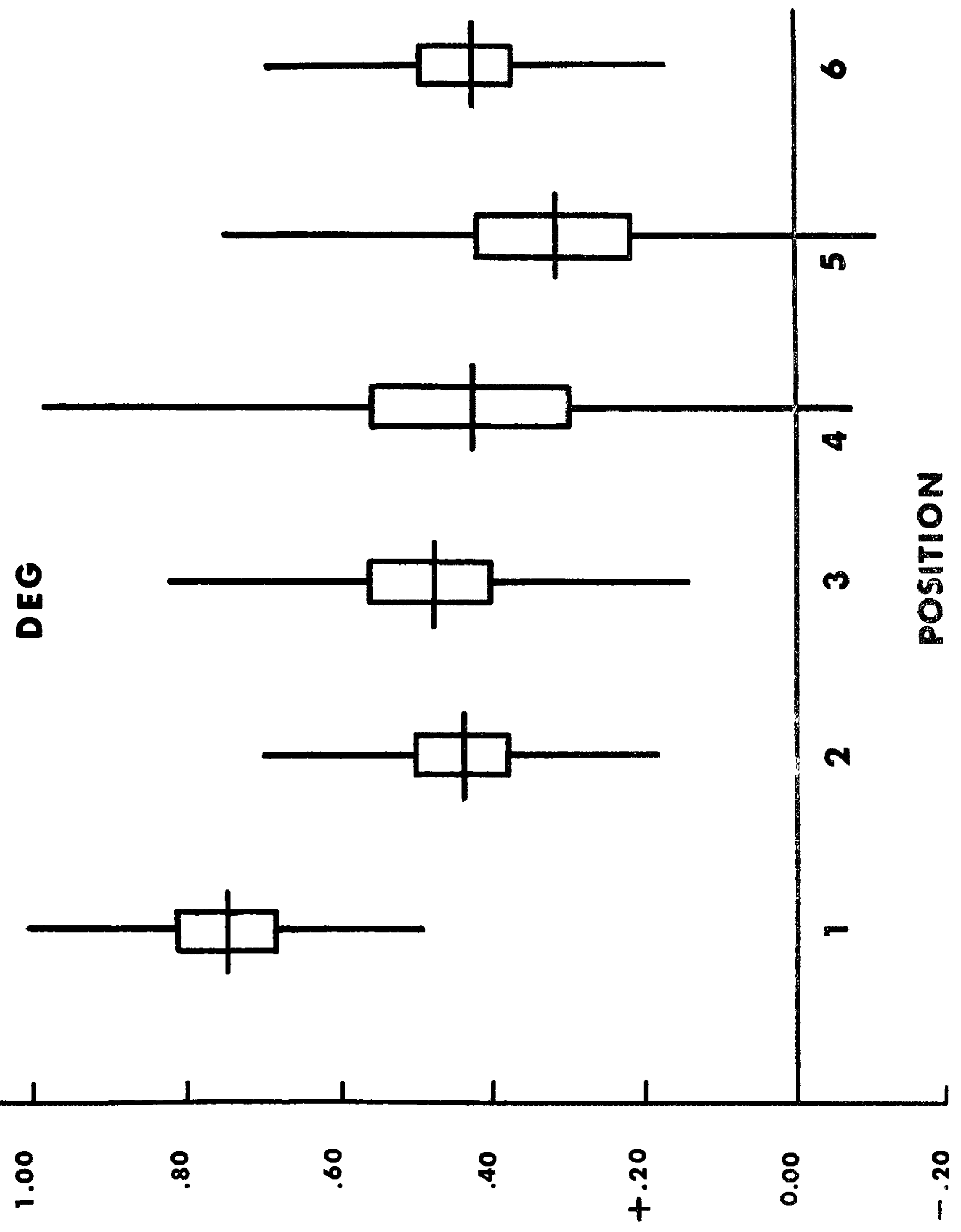


Fig. 9. Effect of position on whether the predator avoided the mimic patterns APFB. Mean number of models not touched minus mean number of mimics not touched. Unhatched includes $A$; hatched excludes A. Position 4 is the model position. Comparison of $\overline{\mathrm{d}}$, standard error of the mean, and ninety-five per cent confidence interval. Symbols as in Fig. 5. 


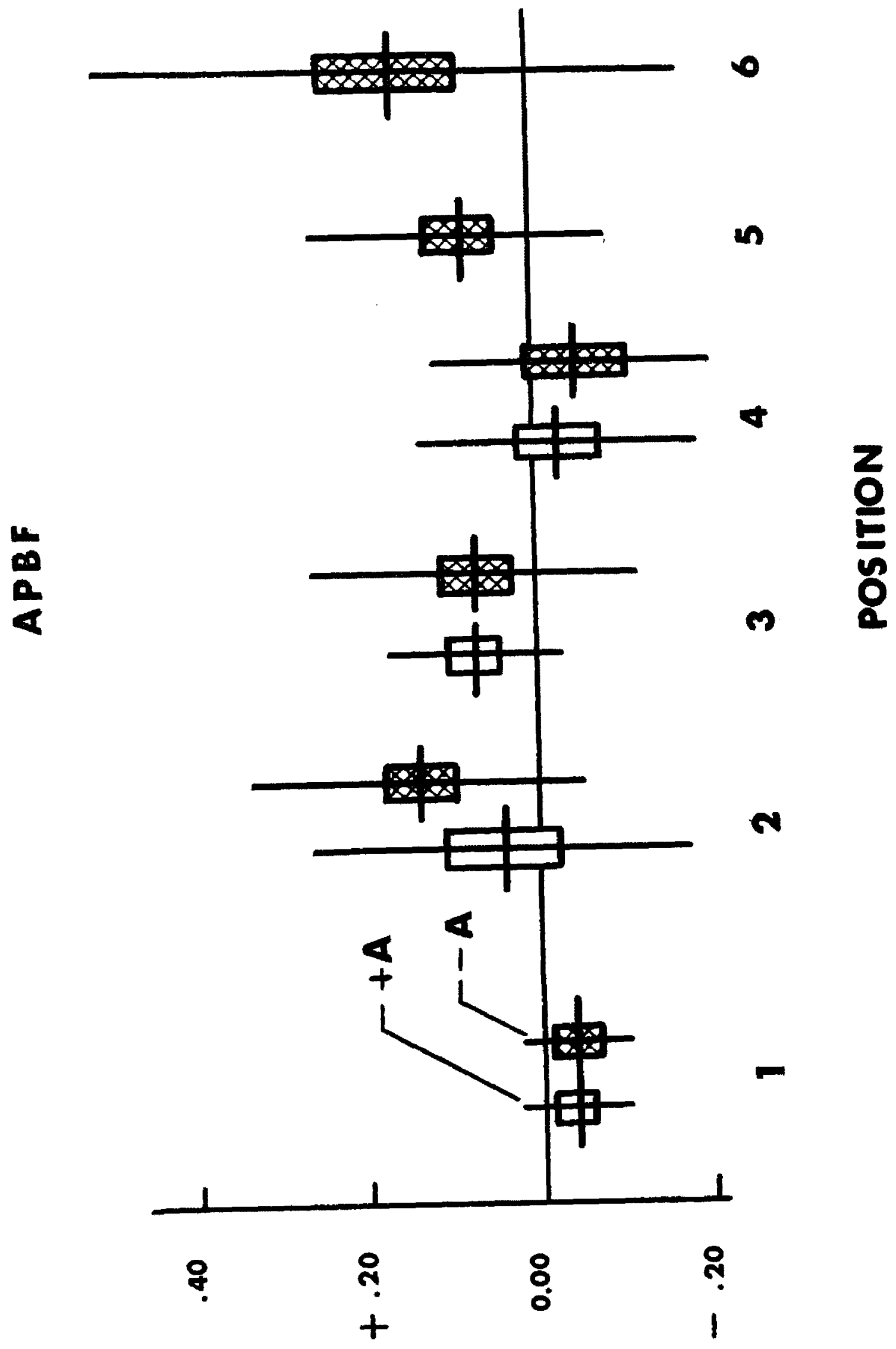


Fig. 10. Effect of position on whether the predator avoided the patterns ECDG. Mean number of models not touched minus mean number of mimics not touched. Hatched excludes G; unhatched includes $\mathrm{G}$. Position 4 is the model position. Comparison of $\overline{\bar{d}}$, standard effor of the mean, and ninetyfive per cent confidence interval. Symbols as in Fig. 5. 


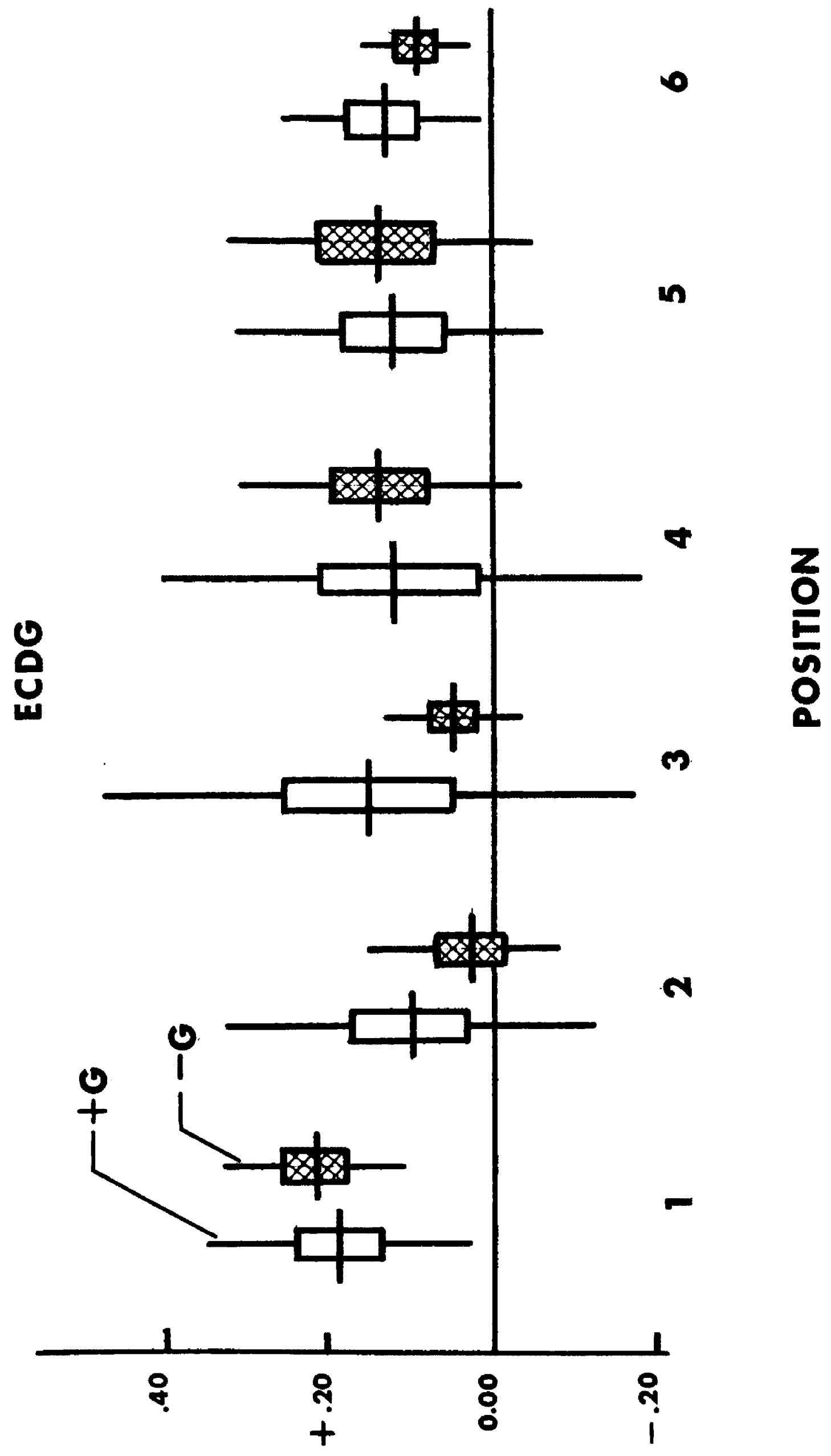

Reproduced with permission of the copyright owner. Further reproduction prohibited without permission. 
The correlation coefficients for position $4 ; 3$ and $5 ; 2$ and 6 ; and 1 , lumped as before, were not significant for either the APBF group $(r=-.010, P>0.1, d f=20)$ or the ECDG group $(r=.103, P>0.1, d f=22)$. The correlation coefficient for APBF from position 1 through 6 tested independently shows a significant positive correlation $(r=.474, P<0.05$, $\mathrm{df}=20)$. There is not significant correlation for the ECDG group $(r=.156$, $P>0.1, d f=22$ ) for positions 1 through 6 .

Each pattern group was then analyzed separately for position changes anteriorly and posteriorly. There was no significant correlation from position 1 through 4 for the ECDG group $(r=-.284, P>0.1$, $\mathrm{df}=14)$, the ECD group $(r=-.273, P>0.1, d f=10)$, the APBF groups $(r=.108, P>0.1, d f=14)$, or the PBF group $(r=-.116, P>0.1, d f=10)$. There was no significant correlation from position 4 through 6 for the ECDG group $(r=.429, P>0.1, d f=10)$ or the ECD group $(r=.260$, $P>0.1, d f=7)$. However there was a significant positive correlation from position 4 through 6 for the PBF group $(r=.725, P<0.02, d f=8)$.

It appears that for the response of not touching, the predators were discriminating the patterns on the posteriormost segments more often than on the anteriormost segments, for those patterns most resembling the model (APBF).

There are pattern-specific differences in the way in which the predators respond to the mimic positions. Although confidence intervals overlapped in all cases, in many cases the standard errors of the mean, 
which account for sixty-eight per cent of the variation about the mean, indicate that there is a slight tendency for patterns to be discriminated differently according to position. For numbers eaten, the mean of position 1 for pattern group DEG appears to be displaced from the others (Fig. 6). Correlation coefficients confirm that predators respond to changes in an anterior direction for this pattern group more readily, and that the remote positions are eaten more often. For numbers not touched, the means for position 4 through 6 show a slight tendency to increase. The correlation coefficients confirm that posterior displacement from the model position is correlated with not touching.

There was no apparent correlation between distance of the mimic's position from the model position and the numbers of mimics eaten or not touched by the predator. Therefore the responses of the birds to the mimics must be influenced primarily by information other than the absolute distance of the mimic position from the model position. Apparently the birds are not basing their response on additional information received from the head and tail of the mealworm. If dis tance were important, there should have been consistent responses to the two pattern groups as distance increased toward the head or toward the tail, and responses to the two pattern groups should not have been the same for anterior and posterior displacement. There is no consistent correlation between the direction (anterior or posterior) of displacement of a mimic position from the model position and the predator's response. 
DISCUSSION

Basic to the micromutational theory of the evolution of mimicry is the requirement that predators generalize by avoiding the poorer mimics more than nonmimetic forms, and discriminate by avoiding the good mimics more than the poorer mimics. An impressive array of investigations has confirmed this (Duncan \& Sheppard 1965; Morrel \& Turner 1970; Schmidt 1960; Sexton 1960). This study has also demonstrated that predators (starlings) can generalize, because even the poorest mimic pattern (G) and position (1) were eaten less than the edibles. In addition, it was shown that the birds could discriminate between patterns, because at least two groups (APFBC and DEG) elicited different responses.

Although this study was not designed to test the sensory bases of the predator's responses to the various patterns, some speculative comments can be made. Apparently the birds do not respond to the total amount of green color on the mealworm. C and E each consist of a single horizontal or vertical stripe, but they were not responded to similarly. D, which has more green than C, was nevertheless eaten and touched more than C. However, it is interesting that in comparing mimics and models not touched, which is probably the best indication of visual discriminatory ability, the $\overline{\bar{d}}$ 's for $\mathrm{C}$ and $\mathrm{E}$ were quite close (Fig. 3). 
Orientation of the stripes on the body axis does appear to be important. $\mathrm{D}$ and $\mathrm{E}$ were parallel to the body axis, and responded to similarly by the predators. B and C were perpendicular to the body axis and responded to similarly, but differently than D and E.

The criteria for pattern A being a "supernormal" stimulus have been met. Tinbergen (1969) defines a supernormal stimulus as one which is more effective than the "natural stimulus" (in this case, the model's pattern) in eliciting a response (in this case, avoidance of the mimic). Pattern A was not touched more than the other patterns (Fig. 3), and in fact was not touched more than the model ( $\overline{\bar{d}}$ for $A$ is negative). Thus, in terms of visual discrimination at least, pattern $A$ was more effective in eliciting avoidance by the starlings than was the model.

The conclusion that clues from the head or tail of the mealworm do not influence the starling's response to the mimics is surprising, especially because the human observer can readily distinguish head and tail. How $\in$ ver, as Hinde (1970) points out, not all available stimuli are used by the animal in solving a discrimination problem. Furthermore, Duncan \& Sheppard (1965) showed that the relative amount of discrimination and generalization used by their experimental animals (chickens) deperded on the degree of distastefulness of the model. Predators reinforced with a very distasteful model would generalize more and discriminate less than predators reinforced with 
only a mildly distasteful model. In the present study, no assessment was made of the distastefulness of the sixty-six per cent solution of quinine dihydrochloride. However, all birds reacted violently to the first contact with the model. The bird would shake its head rapidly back and forth in a horizontal plane, usually expelling the mealworm, then ruffle its feathers, and wipe its beak back and forth across the cage wire or its perch. This reaction of ten occurred whenever the starling picked up a model throughout the experiment. It occasionally also occurred when the starling sampled a mimic. The behaviour of the birds suggests that the solution used was very distasteful to them. Therefore it is not unreasonable to assume that the birds might have discriminated better among mimic patterns and positions if a less distasteful solution had been used. In this case, perhaps information from the head and tail would also have been used. Greater differences between patterns, and possibly even more so between positions, might have been shown.

The fact that the birds are able to discriminate between patterns and between positions is important. So is the fact that the interaction of these two factors is significant. The importance of even extremely small selective advantages $(0.001)$ to a population has been discussed by Dobzhansky (1951) and Duncan \& Sheppard (1965). Such a selective advantage could arise by a relatively minor phenotypic change resulting in a palatable individual acquiring a portion of the pattern of 
an unpalatable species. In this experiment a mimic pattern suggestive of a relatively minor phenotypic change is G1, a small patch of green located on the position most remote from the model position. G1 provides significant protection against predation. Further, minor changes in the positioning of that pattern could give that individual a slight selective advantage over other individuals. That relatively minor changes in a mimetic pattern, color, or position can have a significant effect on a predator's discrimination or generalization has been shown by this study and other studies. These results are consistent with the micromutational theory of the evolution of mimicry.

In this study of imperfect mimicry equal proportions of mimics and models were used. Preliminary investigation by this author indicates that even at low densities (ten per cent mimics, ninety per cent models) approximately ten to twenty per cent of the mimics escaped predation. Further investigation is needed about the effect of varying relative densities of mimics and models and the predator's ability to discriminate and generalize in an imperfect mimicry situation. Mimics presumably evolve at low densities in the early stages under natural conditions, and this type of analysis could offer further evidence to support or contradict the micromutational theory of the evolution of mimicry. 


\section{SUMMARY}

Batesian mimicry was studied in a laboratory situation using caged starlings as the predator and painted mealworms as the artificial prey. Various mimic patterns bearing imperfect resemblances to the model, with the patterns on segments of the mimic different from those of the model, were offered to the birds to test whether the birds responded differently to the various combinations of patterns and positions.

The experimental procedure consisted of offering each bird 50 models, 50 mimics, and 100 edibles over a ten-day period. Models were all painted with a uniform green pattern and dipped in quinine dihydrochloride. Mimics were painted green with one of eight patterns (seven imperfect, and one perfect imitation) and dipped into distilled water. Edibles were painted with colorless paint and dipped into distilled water. Each mealworm was presented singly, and the bird responded by pecking, eating, or not touching the worm.

The mimics were eaten significantly less than the edibles, and the birds were able to generalize from the model to the mimics. Even the least perfect mimic escaped some predation. The birds could discriminate between some patterns and positions which were eaten less often than were others. Three pattern groups (APBFC, DE, and G) resulted. Position was also shown to be important. In the different pattern groups, the remote positions were eaten more, or avoided less, 
than the positions nearer the model position.

The birds did not appear to respond by eating more or avoiding less as the mimic position was displaced further, regardless of direction, from the model position. Nor did the birds appear to be utilizing information received from the head or tail of the mealworm. Rather the birds responded to distance from the model position in an anterior direction in one case, and posterior direction in another case.

This study supports the micromutational theory of the evolution of mimicry. 


\section{REFERENCES}

Brower, J. V. Z. (1958a). Experimental studies of mimicry in some North American butterflies. Part I. The Monarch, Danaus plexippus, and the Viceroy, Limenitis archippus archippus. Evolution, 12, 32-47.

Brower, J. V. Z. (1958b). Experimental studies of mimicry in some North American butterflies. Part II. Battus philenor and Papilio troilus, P. glaucus, and $\underline{P}$. polyxenes. Evolution, 12, 123-136.

Brower, J. V. Z. (1958c). Experimental studies of mimicry in some North American butterflies. Part III. Danaus gilippus berenice and Liminitis archipplus floridensis. Evolution, 12, 273-285.

Brower, J. V. Z. (1960). Experimental studies of mimicry. IV. The reaction of starlings to different proportions of models and mimics. Amer. Nat. , 94, 271-282.

Brower, J. V. Z. (1963). Experimental studies and new evidence of the evolution of mimicry in butterflies. Proc. XVI Intl. Cong. Zool. Wash. 4, 156-161.

Brower, J. V. Z. \& Brower, L:。 P. (1962). Experimental studies of mimicry. IV. The reaction of toads (Bufo terrestris) to honey bees (Apis mellifera) and their dronefiy mimics (Eristalis vintorum). Amer. Nat., 99, 297-307.

Brower, J. V. Z. \& Brower, L. P. (1965). Experimental studies of mimicry. VIII. Further investigations of honeybees (Apis mellifera) and their dronefly mimics (Eristalis vintorum). Amer. Nat., 99, 173-188.

Brower, L. P., Brower, J. V. Z. \& Westcott, P.W. (1960). Experimental studies of mimicry. $V$. The reactions of toads (Bufo terrestris) to bumblebees (Bombus americanorum) and their robberfly mimics (Mallaphora bomboides), with a discussion of aggressive mimicry. Amer. Nat., 94, 343-356.

Brower, L. P., Cook, L. M. \& Croze, H. L. (1967). Predator response to artificial Batesian mimics released in a neotropical environment. Evolution, 21, 11-23. 
Dobzhansky, T. (1951). Genetics and the Origin of Species (3rd ed.). New York: Columbia University Press.

Duncan, C. J. \& Sheppard, P. M. (1965). Sensory discrimination and its role in the evolution of Batesian mimicry. Behaviour, 24 , 269-282.

Fisher, R. A. (1958). The Genetical Theory of Natural Selsction (2nd ed.). New York: Dover Press.

Ford, E. B. (1964). Ecological Genetics. London: Methuen.

Hinde, R. A. (1970). Animal Behaviour. New York: McGraw-Hill.

Morrel, G. M. \& Turner, J. R. (1970). Experiments on mimicry:

II. The response of wild birds to artificial prey. Behaviour, $36,116-130$.

Schmidt, R. S. (1960). Predator behavior and the perfection of incipient mimetic resemblances. Behaviour, 16, 149-158.

Sexton, O. J. (1960). Experimental studies of artificial Batesian mimics. Behaviour, 15, 244-252.

Siegel, S. (1956). Nonparametric Statistics. New York: McGraw-Hill.

Simpson, G. G., Roe, A. \& Lewontin, R. C. (1960). Quantitative

Zoology. New York: Harcourt, Brace, \& World.

Tinbergen, N. (1965). Behaviour and natural selection. In: Ideas in

Evolution and Behavior (Ed. by J. A. Moore). New York:

Natural History Press.

Tinbergen, N. (1969). The Study of Instinct (2nd ed.). Oxford:

Clarendon Press.

Wickler, W. (1968). Mimicry in Plants and Animals. New York:

McGraw-Hili. 
Appendix A. Wilcoxson Matched Pairs Signed Ranks Test. Difference between mean number of edibles eaten and mean number of mimics eaten for all combinations. N=number of matched pairs; $T=$ smaller sum of like-signed ranks Siegel 1956).

$\begin{array}{lllllll}1 & 2 & 3 & 4 & 5 & 6\end{array}$

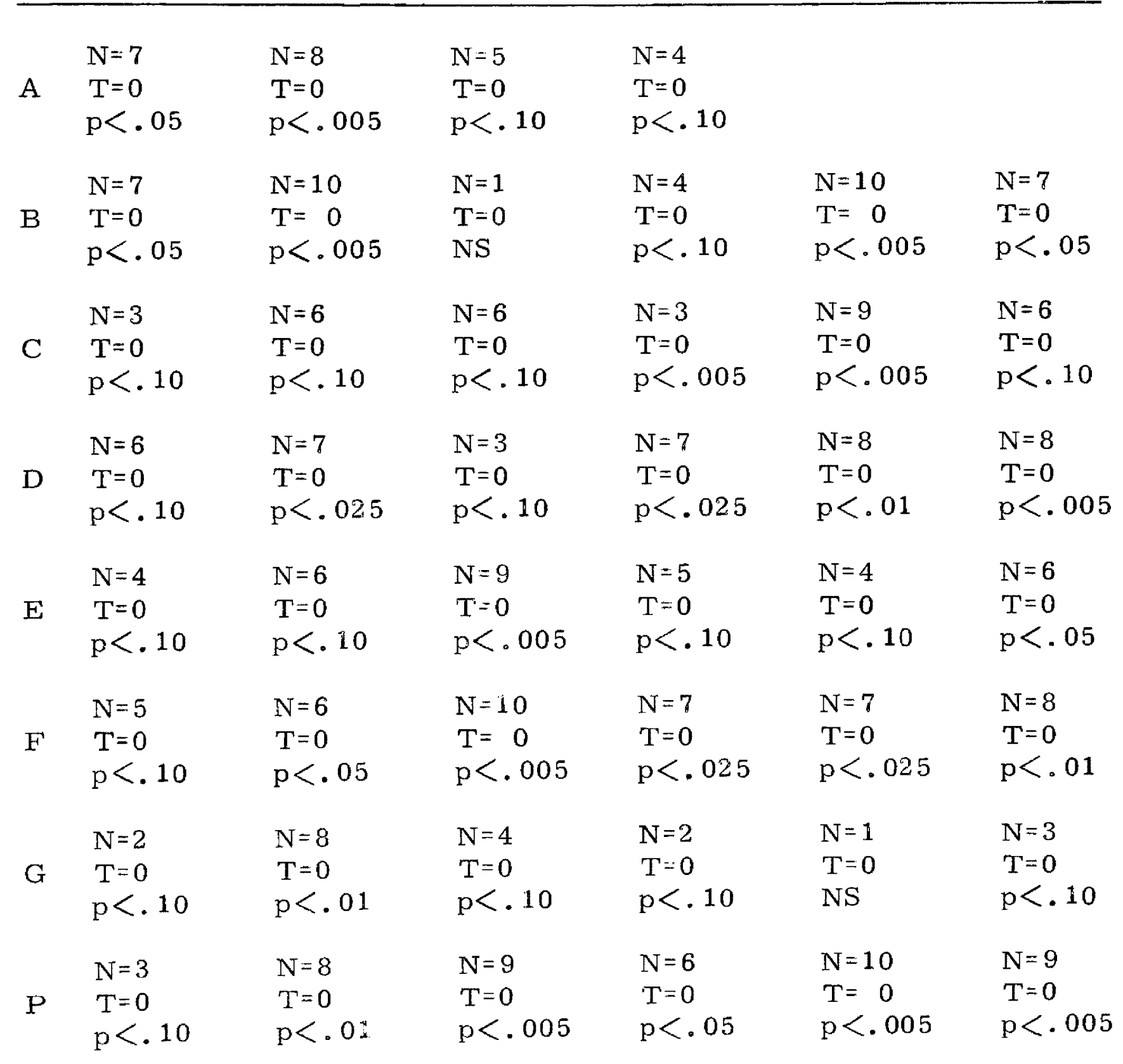


Appendix B. Wilcoxson Matched Pairs Signed Ranks Test. Difference between time required to eat mimics and time required to eat edibles, for those eaten only. $N, T$ as in Appendix A.

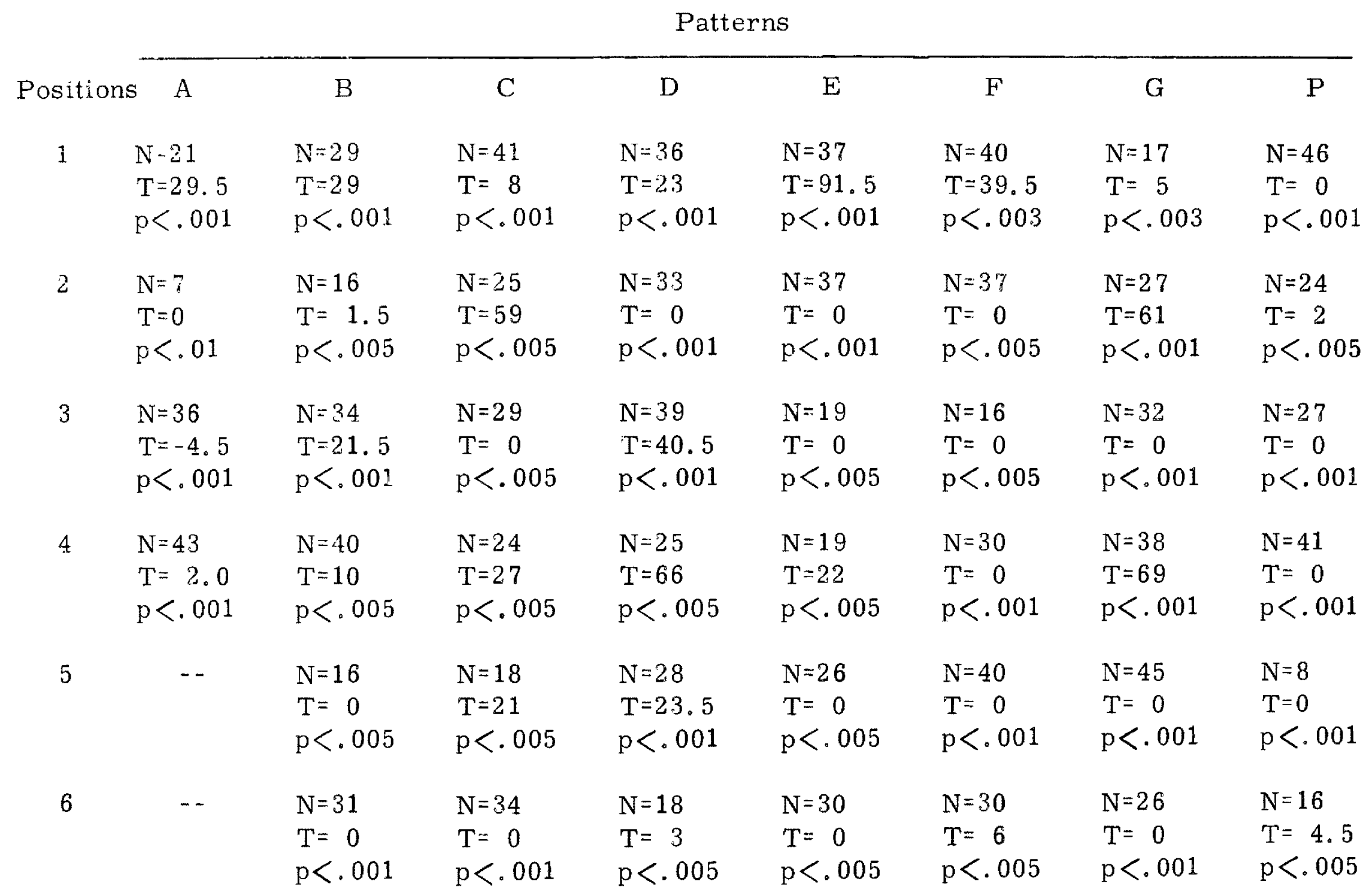


Appendix C. Wilcoxson Matched Pairs Signed Ranks Test for All Combinations. Difference between mean number mimics eaten and mean number of models eaten. $\mathrm{N}, \mathrm{T}$ as in Appendix A.

\begin{tabular}{|c|c|c|c|c|c|c|c|c|}
\hline \multirow[b]{2}{*}{ Positions } & \multicolumn{8}{|c|}{ Patterns } \\
\hline & $\mathrm{A}$ & B & $\mathrm{C}$ & $\mathrm{D}$ & $\mathrm{E}$ & $\mathrm{F}$ & G & $P$ \\
\hline \multirow[t]{3}{*}{1} & $N=9$ & $N=6$ & $\mathrm{~N}=9$ & $\mathrm{~N}=10$ & $\mathrm{~N}=10$ & $N=4$ & $N=10$ & $N=6$ \\
\hline & $\mathrm{T}=9$ & $T=4$ & $T=0$ & $\mathrm{~T}=0$ & $T=0$ & $\mathrm{~T}=2.5$ & $T=0$ & $\mathrm{~T}=2.5$ \\
\hline & $p=.05$ & $p=.08$ & $p<.005$ & $\mathrm{p}<.005$ & $p<.005$ & $p=.18$ & $p<.005$ & $p=.05$ \\
\hline \multirow[t]{3}{*}{2} & $N=7$ & $N=8$ & $N=8$ & $\mathrm{~N}=8$ & $N=10$ & $N=9$ & $N=9$ & $N=6$ \\
\hline & $T=4$ & $T=5$ & $T=10$ & $T=1.5$ & $T=0$ & $\mathrm{~T}=4$ & $T=0$ & $T=0$ \\
\hline & $p=.045$ & $p-.03$ & $p=.13$ & $\mathrm{p}<.01$ & $p<.005$ & $p<.025$ & $\mathrm{p}<.005$ & $p=.025$ \\
\hline \multirow[t]{3}{*}{3} & $\mathrm{~N}=10$ & $N=8$ & $N=7$ & $\mathrm{~N}=10$ & $N=8$ & $N=7$ & $\mathrm{~N}=10$ & $\mathrm{~N}=9$ \\
\hline & $\mathrm{T}=0$ & $T=1.5$ & $T=4$ & $\mathrm{~T}=0$ & $\mathrm{~T}=0$ & $T=0$ & $\mathrm{~T}=1.5$ & $\mathrm{~T}=0$ \\
\hline & $p<.005$ & $\mathrm{p}<.005$ & $p=.04$ & $\mathrm{p}<.005$ & $\mathrm{p}<.005$ & $p<.01$ & $\mathrm{p}<.005$ & $\mathrm{p}<.005$ \\
\hline \multirow[t]{3}{*}{4} & $N=5$ & $N=3$ & $N=9$ & $N=8$ & $N=10$ & $N=?$ & $N=10$ & $N=9$ \\
\hline & $T=0$ & $\mathrm{~T}=0$ & $T=0$ & $\mathrm{~T}=4$ & $\mathrm{~T}=3$ & $T=2.5$ & $T=0$ & $T=0$ \\
\hline & $p=.02$ & $p=.005$ & $\mathrm{p}<.005$ & $p=.025$ & $p<.005$ & $p=.03$ & $p<.005$ & $p<.005$ \\
\hline \multirow[t]{3}{*}{5} & -- & $N=9$ & $N=8$ & $\mathrm{~N}=10$ & $N=9$ & $N=8$ & $N=6$ & $N=5$ \\
\hline & & $\mathrm{T}=0$ & $T=2.5$ & $T=1$ & $\mathrm{~T}=0$ & $\mathrm{~T}=3.5$ & $\mathrm{~T}=0$ & $\mathrm{~T}=2.5$ \\
\hline & & $\mathrm{p}<.005$ & $p=.025$ & $\mathrm{p}<.005$ & $\mathrm{p}<.005$ & $p<.025$ & $p<.025$ & $p=.09$ \\
\hline \multirow[t]{3}{*}{$\varepsilon$} & - & $N=10$ & $N=8$ & $N=7$ & $N=10$ & $N=9$ & $\mathrm{~N}=9$ & $N=9$ \\
\hline & & $\mathrm{T}=0$ & $T=0$ & $\mathrm{~T}=0$ & $\mathrm{~T}=2$ & $\mathrm{~T}=3$ & $\mathrm{~T}=0$ & $\mathrm{~T}=9$ \\
\hline & & $p<.005$ & $p<.005$ & $p<.01$ & $p<.005$ & $p=.01$ & $p<.005$ & $p=.06$ \\
\hline
\end{tabular}


Appendix D. Wilcoxs on Matched Pairs Signed Ranks Test for All Combinations. Difference betwe mean number of models not touched and mean number of mimics not touched. $\mathrm{N}, \mathrm{T}$ as in Appendix A.

\section{Patterns}

\begin{tabular}{|c|c|c|c|c|c|c|c|c|}
\hline Positions & A & $\mathrm{B}$ & $\mathrm{C}$ & $\mathrm{D}$ & $\mathrm{E}$ & $\mathrm{F}$ & $\mathrm{G}$ & $P$ \\
\hline \multirow[t]{3}{*}{1} & $N=9$ & $N=6$ & $N=5$ & $N=10$ & $N=8$ & $\mathrm{~N}=0$ & $N=6$ & $\mathrm{~N}=0$ \\
\hline & $\mathrm{T}=21$ & $T=2.5$ & $\mathrm{~T}=0$ & $\mathrm{~T}=3$ & $\mathrm{~T}=2.5$ & & $\mathrm{~T}=3$ & \\
\hline & $p=.47$ & $p=.10$ & $\mathrm{p}=.05$ & $\mathrm{p}<.005$ & $\mathrm{p}<.05$ & NS & $p=.06$ & NS \\
\hline \multirow[t]{3}{*}{2} & $N=9$ & $N=8$ & $N=8$ & $N=5$ & $N=7$ & $N=6$ & $N=9$ & $\mathrm{~N}=8$ \\
\hline & $\mathrm{T}=0$ & $\mathrm{~T}=10.5$ & $T=\rfloor 0$ & $\mathrm{~T}=4.5$ & $\mathrm{~T}=10.5$ & $\mathrm{~T}=4$ & $\mathrm{~T}=5.5$ & $\mathrm{~T}=8$ \\
\hline & $p<.005$ & $p=.14$ & $p=.13$ & $p=.20$ & $p=.28$ & $p=.09$ & $p=.025$ & $p=.08$ \\
\hline \multirow[t]{3}{*}{3} & $\mathrm{~N}=4$ & $\mathrm{~N}=1$ & $\mathrm{~N}=7$ & $N=2$ & $N=6$ & $N=8$ & $\mathrm{~N}=10$ & $N=8$ \\
\hline & $\mathrm{T}=4$ & $\mathrm{~T}=0$ & $\mathrm{~T}=11.5$ & $T=0$ & $\mathrm{~T}=2$ & $\mathrm{~T}=9.5$ & $\mathrm{~T}=1.5$ & $\mathrm{~T}=10.5$ \\
\hline & $p=.36$ & $p=N S$ & $p=.34$ & $p=.10$ & $\mathrm{p}<.005$ & $p=.115$ & $\mathrm{p}<.005$ & $p=.14$ \\
\hline \multirow[t]{3}{*}{4} & $N=5$ & $\mathrm{~N}=?$ & $N=8$ & $N=7$ & $N=4$ & $N=: 7$ & $\mathrm{~N}=4$ & $N=4$ \\
\hline & $\mathrm{T}=7.5$ & $T=0$ & $T=0$ & $\mathrm{~T}=6$ & $T=3$ & $T=12$ & $\mathrm{~T}=1.5$ & $\mathrm{~T}=\mathrm{2}$ \\
\hline & $\mathrm{NS}$ & $\mathrm{p}<.0 \mathrm{i}$ & $p<.005$ & $p=.09$ & NS & $p=.33$ & $p=.09$ & $p=.13$ \\
\hline \multirow[t]{3}{*}{5} & $=-$ & $N=6$ & $N=6$ & $N=9$ & $N=5$ & $N=3$ & $\mathrm{~N}=4$ & $N=8$ \\
\hline & & $\mathrm{T}=0$ & $T=8.5$ & $\mathrm{~T}=2.5$ & $T=0$ & $\mathrm{~T}=0$ & $\mathrm{~T}=0$ & $\mathrm{~T}=16.5$ \\
\hline & & $\mathrm{p}<.10$ & $p=.33$ & $p<.01$ & $p<.05$ & $p=.05$ & $p=.03$ & NS \\
\hline \multirow[t]{3}{*}{6} & -- & $N=7$ & $N=8$ & $N=8$ & $N=7$ & $N=7$ & $N=7$ & $N=8$ \\
\hline & & $T=0$ & $\mathrm{~T}=8$ & $T=17.5$ & $\mathrm{~T}=7$ & $\mathrm{~T}=0$ & $\mathrm{~T}=0$ & $\mathrm{~T}=10.5$ \\
\hline & & $p<.025$ & $p=.08$ & NS & $p=.11$ & $p=.01$ & $\mathrm{p}<.01$ & $p=.14$ \\
\hline
\end{tabular}

